\title{
10 PERGUNTAS \\ E RESPOSTAS \\ PARA \\ COMPREENDER
}
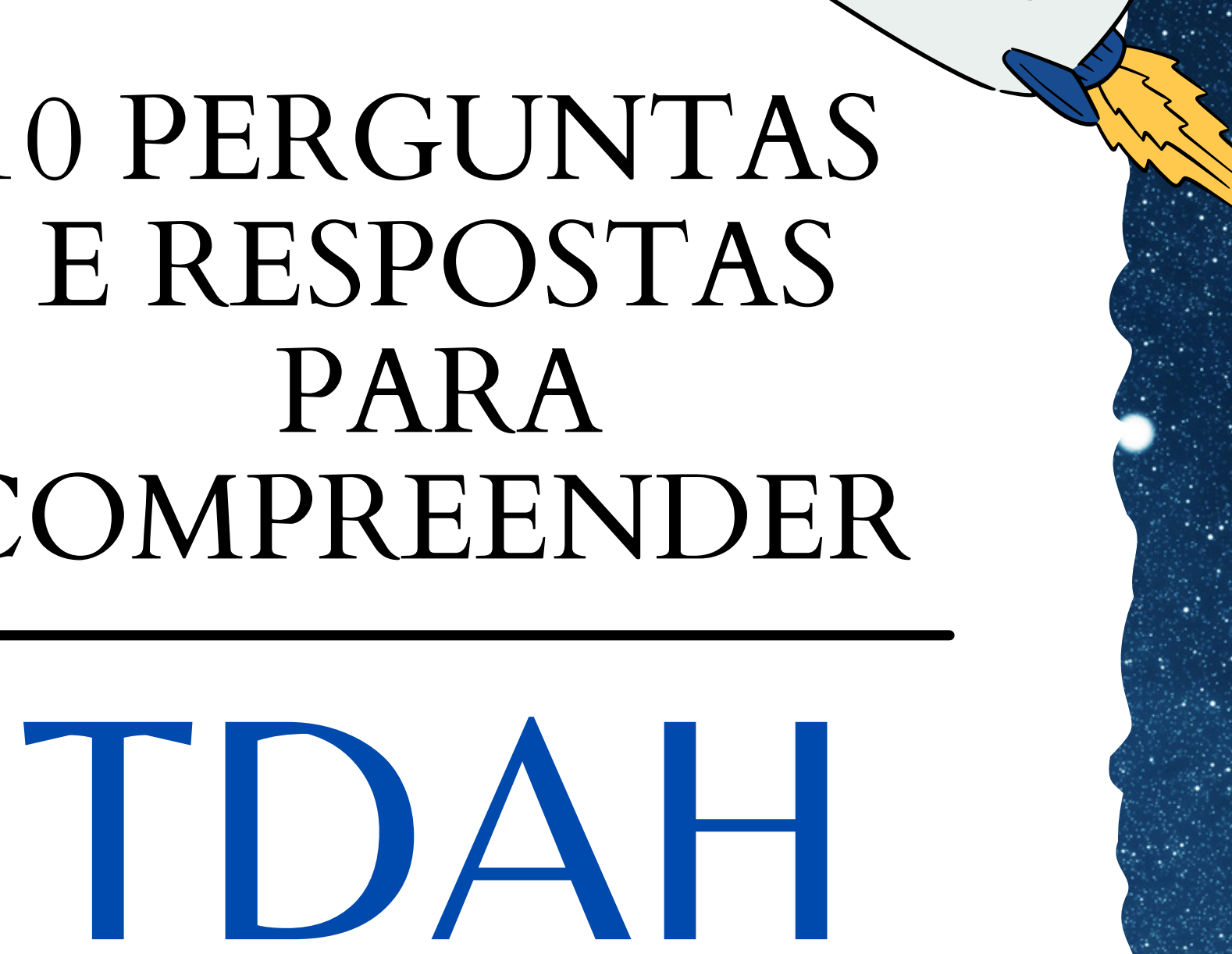

\section{Patrícia Gonçalves e Glauce Thais B.S. Barros Bacellar \\ Diagramação: Jéssica Helena Castilho}

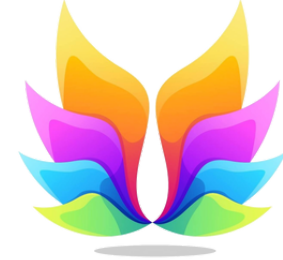

Editora Dialética e Realidade

(

2021 


\section{PATRÍCIA GONÇALVES}

GLAUCE THAIS B. S. BARROS BACELAR

10 PERGUNTAS E RESPOSTAS PARA COMPREENDER A TDAH

Editora Dialética e Realidade

Curitiba

2021 
Os livros do selo Dialética e Realidade apresentam resultados de pesquisas desenvolvidas por professores e pesquisadores em formato eletrônico com licenciamento (CC BY + NC). A proposta de tratamento dialético busca estabelecer a verdade por meio de argumentos que esclareçam aspectos de interesse para a comunidade acadêmica e para a sociedade de forma geral.

\begin{tabular}{|ll} 
Dados Comerciais \\
\hline Rua & Alberto Rutz 491 - Casa 4 \\
Cidade & Curitiba \\
Bairro & Portão \\
CEP & 81320280 \\
Site & http://dialeticaerealidade.com \\
E-mail & dialeticaerealidade@gmail.com
\end{tabular}

Editora chefe Prof. ${ }^{a}$ Dr. ${ }^{a}$ Dinamara Pereira Machado

Responsável técnico Prof. Dr. Antonio Siemsen Munhoz Aprendiz técnica Fabíola Ribeiro Vieira

\section{Conselho Editorial Nacional}

\begin{tabular}{|c|c|c|}
\hline Prof. & Dr. & Adriano Souza Lima \\
\hline Prof. & Dr. & André Luiz Cavazzani Moskaleski \\
\hline Prof. & Dr. & Antonio Siemsen Munhoz \\
\hline Prof. a & Dr.a & Andréia Furtado \\
\hline Prof. & Me. & Armando Kolbe Júnior \\
\hline Prof. & Dr. & Cícero Manoel Bezerra \\
\hline Prof. ${ }^{a}$ & Dr. ${ }^{a}$ & Deisily de Quadros \\
\hline Prof. ${ }^{a}$ & Dr. ${ }^{a}$ & Dinamara Pereira Machado \\
\hline Prof. & Me. & Edvaldo Luiz Rando Junior \\
\hline Prof. ${ }^{a}$ & Dr. ${ }^{a}$ & Flávia Brito Dias \\
\hline Prof. & Dr. & Guilherme Augusto Pianezzer \\
\hline Prof. ${ }^{a}$ & Dr. ${ }^{a}$ & Gisele do Rocio Cordeiro \\
\hline
\end{tabular}




\begin{tabular}{|c|c|c|}
\hline Prof. ${ }^{a}$ & Dr. $^{\mathrm{a}}$ & Katiuscia Mello Figuerôa \\
\hline Prof. & & Luis Fernando Lopes \\
\hline Prof. ${ }^{a}$. & Dr. ${ }^{a}$ & Leociléa Aparecida Vieira \\
\hline Prof. & Dr. & Marcos Ruiz da Silva \\
\hline Prof. ${ }^{a}$ & Esp. & Maria Teresa Xavier Cordeiro \\
\hline Prof. & Dr. ${ }^{a}$ & Marilene Garcia \\
\hline Prof.a ${ }^{a}$ & Dr. ${ }^{a}$ & Márcia Regina Mocelin \\
\hline Prof. ${ }^{a}$ & Dr. ${ }^{a}$ & Naura Garcia Carapeto Ferreira \\
\hline Prof. & Me. & Paulo Martinelli \\
\hline Prof. & Dr. & Rafael Pereira Dubiela \\
\hline Prof. ${ }^{a}$ & Dr. $^{\mathrm{a}}$ & Roberta Ravaglio Gagno \\
\hline Prof. ${ }^{a}$ & Dr. ${ }^{a}$ & Renata Adriana Garbossa Silva \\
\hline Prof. ${ }^{a}$ & Me. & Renata Burgo Fedato \\
\hline Prof. ${ }^{a}$ & Dr. ${ }^{a}$ & Tatiane Calve \\
\hline Prof. ${ }^{a}$ & Me. & Thiana Maria Becker \\
\hline Prof. a & Dr. ${ }^{a}$ & Tatiane Calve \\
\hline
\end{tabular}

\section{Conselho Editorial Internacional}

Prof. Dr. Santiago Castillo Arredondo

Prof. ${ }^{a} \quad$ Dr. ${ }^{a}$ Maria Esther Martinez Quinteiro

O projeto publicação acadêmica reúne um grupo de pesquisadores especializados e independentes provenientes de diferentes IES em nível global. Ele está desenhado com a integração de diversas áreas do conhecimento. Seu objetivo é a abertura de um canal de comunicação utilizado para divulgação de estudos e pesquisas acadêmicas. A participação não resulta em remuneração financeira de nenhuma espécie. Os únicos recursos financeiros envolvidos são aqueles devidos ao registro do ISBN, do código de barras e da ficha catalográfica. Custos administrativos poderão ser rateados entre os participantes. Os textos publicados são de total responsabilidade de seus autores. 
Esta obra está sendo entregue aos leitores na modalidade creative commons licenciada de acordo com os seguintes termos cc by+nc. Esta indicação permite que a obra seja utilizada de forma livre, referenciando o autor e não utilizando o material com finalidades comerciais.

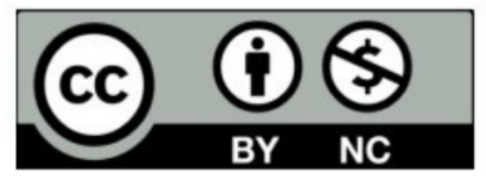

Dados Internacionais de Catalogação na Publicação (CIP) (Câmara Brasileira do Livro, SP, Brasil)

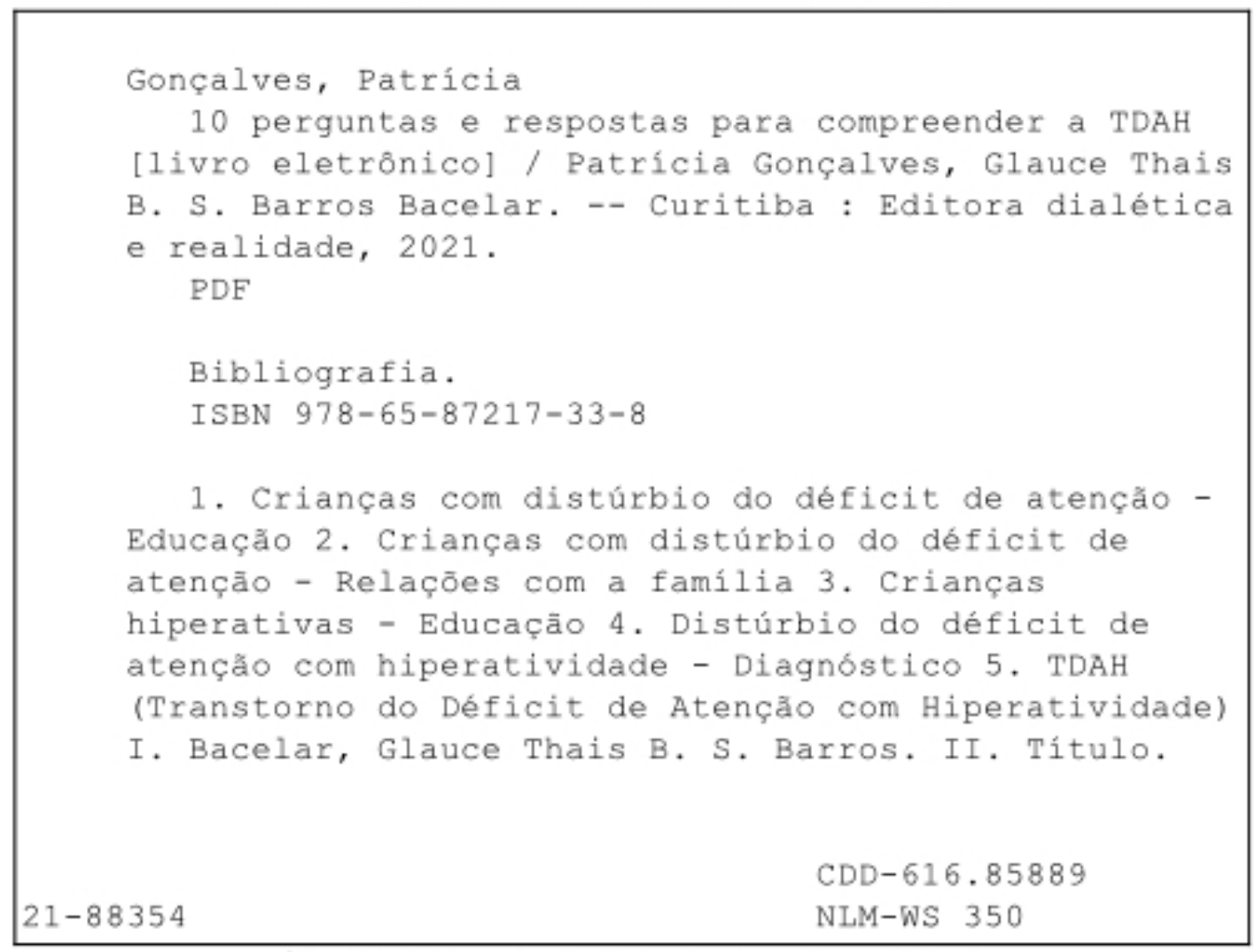

Índices para catálogo sistemático:

1. Transtorno de Déficit de Atenção com

Hiperatividade : Ciências médicas 616.85889

Eliete Marques da Silva - Bibliotecária - CRB-8/9380

\section{REFERÊNCIA BÁSICA}

Gonçalves, Patrícia; Bacelar Glauce Thais B. S. Barros. 10 perguntas

e respostas para compreender a TDAH. Curitiba: Editora Dialética e Realidade, 2021.

Há cartas de concordância com esta publicação, de acordo com posicionamento de todos os autores, como guardados em arquivos do sistema. A correção do texto, com relação aos elementos componentes foi desenvolvida pelo autor de cada capítulo. 
10 PERGUNTAS E RESPOSTAS PARA COMPREENDER A TDAH

Editora Dialética e Realidade Curitiba

2021 


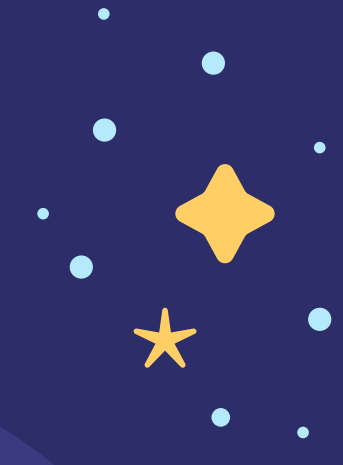

$\bullet$

Dedicamos este e-book a todas as famílias, professores, coordenadores • escolares e profissionais da saúde comprometidos com o desenvolvimento acadêmico e social de nossas crianças,

- que não medem esforços para tornar a vida daqueles que lhes são confiados mais saudável e feliz, combatendo a falta . . de informação, a ignorância e o

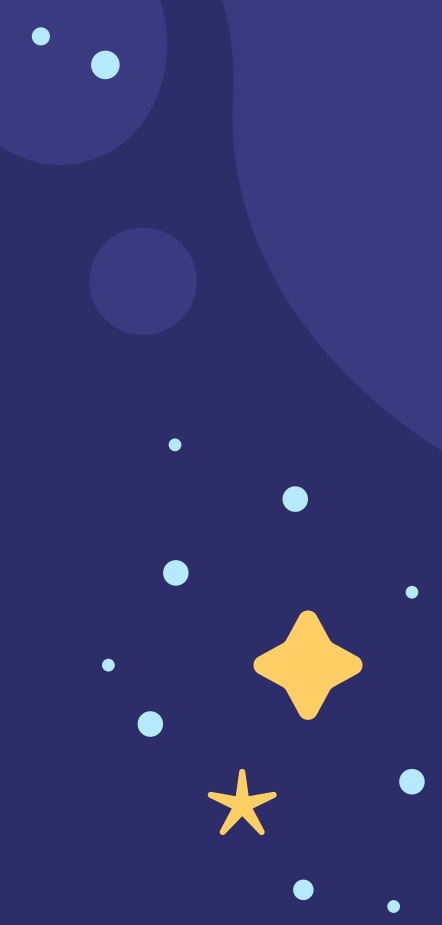
preconceito. 


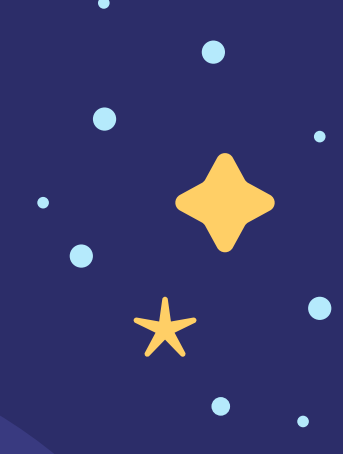

. 


\section{AS

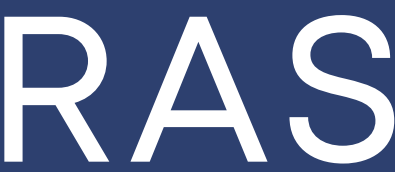

\section{Patrícia Gonçalves}

Graduada em Pedagogia com habilitação em Educação Especial e em Filosofia pela UFPR, Neuropsicopedagoga, Especialista em Metodologia do Ensino de Língua Portuguesa e Literatura, Mestre em Filosofia e Doutora em Educação pela UFPR na linha de pesquisa Cognição, Aprendizagem e desenvolvimento humano. Atualmente leciona no ensino superior, pesquisa o desenvolvimento da inteligência humana,

trabalha diretamente com enriquecimento curricular e assessoria familiar e educacional.

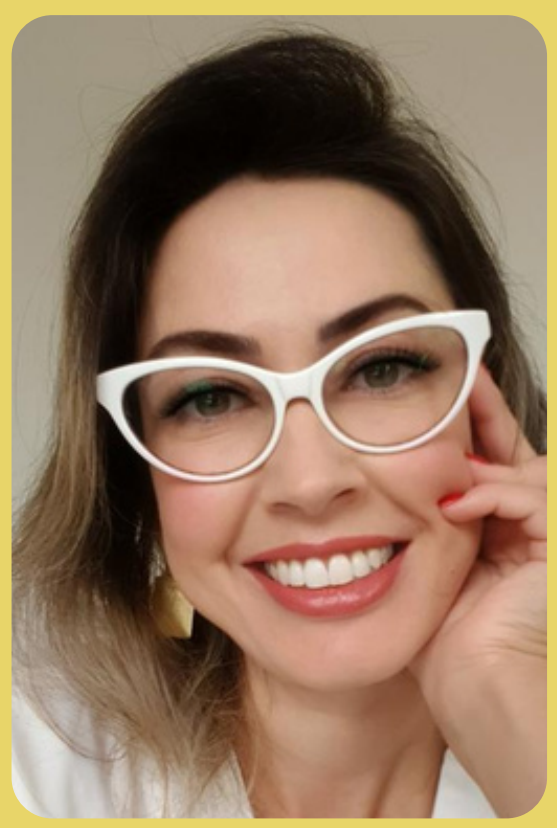

\section{Glauce Thais Bezerra \\ Souza Barros Bacellar}

Formada em Psicologia, Especialista em Psicologia Clínica na abordagem GestaltTerapia, Especialista

em

Altas Habilidades/Superdotação e Mestre em Ensino nas Ciências da Saúde pela Faculdade Pequeno Príncipe - FPP. Realiza pesquisas na área de Educação Inclusiva. Tem experiência em atendimento clínico, avaliação psicológica e avaliação de potencial intelectual para Altas Habilidades/Superdotação.

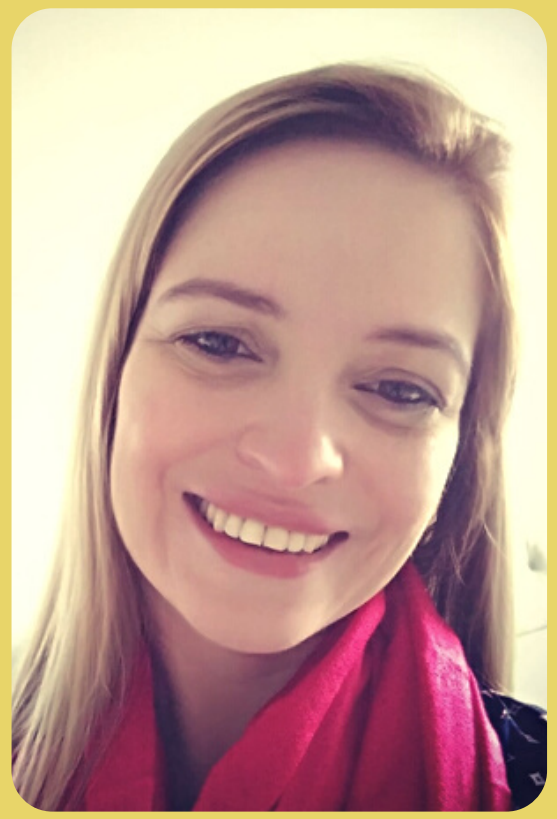


$\downarrow$

\title{
"Ninguém pode ser autenticamente \\ humano, enquanto impede outros de serem também."
}

\author{
Paulo Freire (1974)
}




\section{APRESENTAÇÃO}

Em 1854, as primeiras referências acerca dos transtornos hipercinéticos surgiram na literatura médica, quando o alemão Heinrich Hoffmann escreveu a obra Der Struwwelpeter descrevendo a insanidade impulsiva como o comportamento de crianças hiperativas. Assim, podemos observar que o TDAH não é um diagnóstico da moda, como muito se ouve por aí.

Ao encontro deste e de outros conceitos equivocados a respeito do diagnóstico e dos tratamentos indicados para as pessoas com TDAH, este ebook tem por objetivo ser um material de fácil leitura, fundamentado em autores de referência sobre a área, utilizando uma linguagem dinâmica e acessível para que pais, professores e profissionais da saúde possam adquirir informações, desmistificar conceitos e se despir de preconceitos acerca desta temática. 
Como profissionais que recebem e atendem pessoas com esse tipo de transtorno com os mais acentuados níveis de sofrimento, não podemos deixar de oferecer um material que possibilite a identificação e o atendimento precoce à esta demanda, no intuito não apenas de diagnosticar mas, de promover intervenções clínicas e escolares que venham a oferecer a pessoa com TDAH, a diminuição de seu sofrimento mental e a promoção de sua aprendizagem e do bom convívio escolar.

Desejamos que este material, fruto de uma ampla pesquisa produzida com muito carinho, possa auxiliar a todos que ainda tem suas inquietações mal compreendidas a iniciarem um novo trajeto de descobertas e aventuras por esse caminho nada constante e inerte, que é a própria vida.

Com o desejo de uma excelente leitura, 


\section{PREFÁCIO}

O Transtorno de Déficit de Atenção e Hiperatividade (TDAH) é uma das condições médicas mais intensamente estudadas nos últimos 30 anos. Este processo fora impulsionado pelas evidências clínicas, estudos neuropsicológicos, levado cada vez mais a cabo pelo avanço explosivo das pesquisas médicas neurocientíficas e pela cada vez mais "conectada" rede de avaliações e experiências interdisciplinares - dos laboratórios às escolas. Esta verdadeira rede de informações produziu congressos internacionais, artigos científicos, protocolos de atendimento, pesquisas farmacológicas e não farmacológicas e permitiu a produção de estratégias psicoeducativas ricas e oportunas para estes pacientes em qualquer momento de suas vidas e iluminou o caminho de pais e cuidadores outrora perdidos, enganados ou descrentes. 
Por ser uma condição que não tem exames específicos e depende de tratamentos que envolvem vários atores sociais, não se poderia deixar de lado estratégias que envolvam informações especializadas e obras que trouxessem dicas e formas de manejo para os pais ou cuidadores destas crianças. Muitas pessoas não conhecem o TDAH e muitas vezes o desconhecimento é o fator que mais contribui para o sofrimento de quem tem, assim como alimenta recorrentes perdas de oportunidades tanto nas relações afetivas, sociais, quanto nos processos de aprendizagem escolar.

Neste sentido, este livro traz um conteúdo que vai facilitar o acesso das famílias e dos profissionais de saúde e da educação ao que realmente significa o TDAH e como lidar com os desafios que ele impõe dia a dia na vida de quem tem e de quem convive. Sua linguagem fácil e por meio de apresentações envolventes, ajudarão aos interessados neste tema tecer os melhores caminhos para entender e conduzir estas crianças.

Dr. Clay, Brites Pediatra e Neuralagista Infantil da Instituta Neurasaber Dautor em Ciências Médicas/UNICAMP Membra titular da SBP e SBNi 


\section{SUMÁRIO}

1. O QUE É TDAH?..............................15

2. QUAIS SÃO AS CARACTERÍSTICAS?......20

3. QUEM PODE DIAGNOSTICAR O TDAH?..25

4. COMO É REALIZADO O DIAGNÓSTICO

DO TDAH? ......................................28

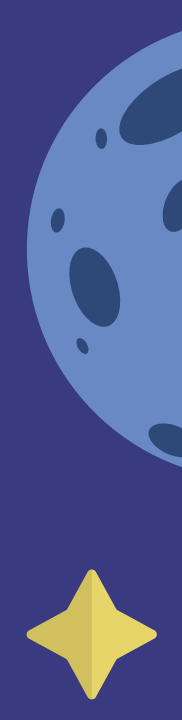

RECOMENDADOS PARA A PESSOA

.33

6. COMO É REALIZADO O DIAGNÓSTICO

DO TDAH?........................................ 37

7. O TDAH PODE ESTAR ASSOCIADO A

OUTROS TRANSTORNOS?

8. QUAL A IMPORTÂNCIA DA FAMÍLIA

PARA O DESENVOLVIMENTO DA PESSOA

COM TDAH?......................................48

9. UM ADULTO PODE TER TDAH?..............52

$\downarrow$ 10. QUAIS OS DESAFIOS DA PESSOA COM

TDAH NA SOCIEDADE?............................58 


\section{O QUE É TDAH?}

O Manual Estatístico e Diagnóstico de Transtornos Mentais, em sua $5^{\text {a }}$ edição (DSM - V), define que o TDAH é uma síndrome que envolve os aspectos de desatenção, hiperatividade e impulsividade. Há 3 tipos: os que são predominantemente desatentos, os que são hiperativo/impulsivos e os combinados. Os critérios clínicos resultam no diagnóstico e o tratamento a seguir é realizado com tratamento farmacológico, terapia comportamental e intervenções educacionais.

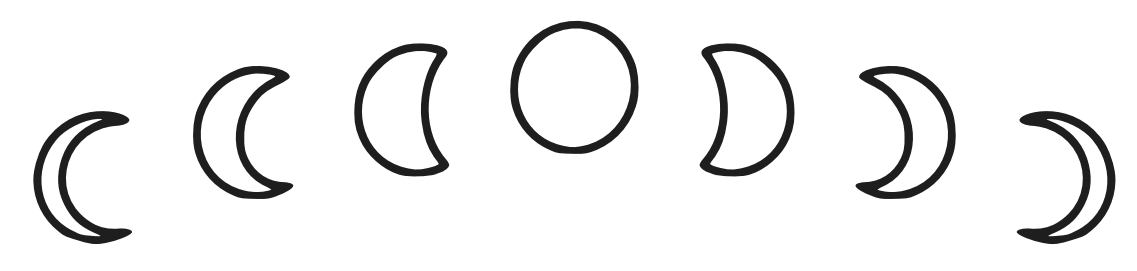

Ao longo do tempo, o TDAH recebeu várias terminologias que estão descritas no Manual Estatístico e Diagnóstico de Transtornos Mentais (DSM). Entre elas, estão: lesão cerebral mínima, disfunção cerebral mínima, hipercinesia, síndrome hipercenética ou impulsiva, reação hipercenética da infância (DSM - II) e déficit de atenção com ou sem hiperatividade (DSM-III). Em 1994, o DSM - IV definiu mais claramente esse transtorno, valorizando também, além da desatenção e hiperatividade, a impulsividade. 
O transtorno na infância é mais frequente em meninos do que em meninas, com uma relação de 2 para 1 . Na idade escolar, a relação entre meninos e meninas aproxima-se de 2 para 1; na adolescência parece haver um equilíbrio de 1 para 1 e nos adultos jovens, ocorre predomínio feminino de 2 para 1 (ROTTA et al, 2016).

A etiologia, ou seja, a causa do TDAH é multifatorial composta por fatores genéticos (importância da transmissão genética do transtorno), fatores não genéticos (presença de anormalidades durante a gestação e parto), fatores neuroanatômicos (alterações em áreas pré-frontais, que são essenciais nos processos de atenção, controle de impulsos, organização e atividade sustentada dirigida a algum fim) ou fatores familiares e psicossociais.

Quanto ao último fator, Condemarín et al (2006) explica que as crianças que apresentam o quadro leve podem piorar de forma relevante, caso não haja suporte familiar ou se não receberem suporte educacional em suas instituição de ensino que não as acolham em suas dificuldades.

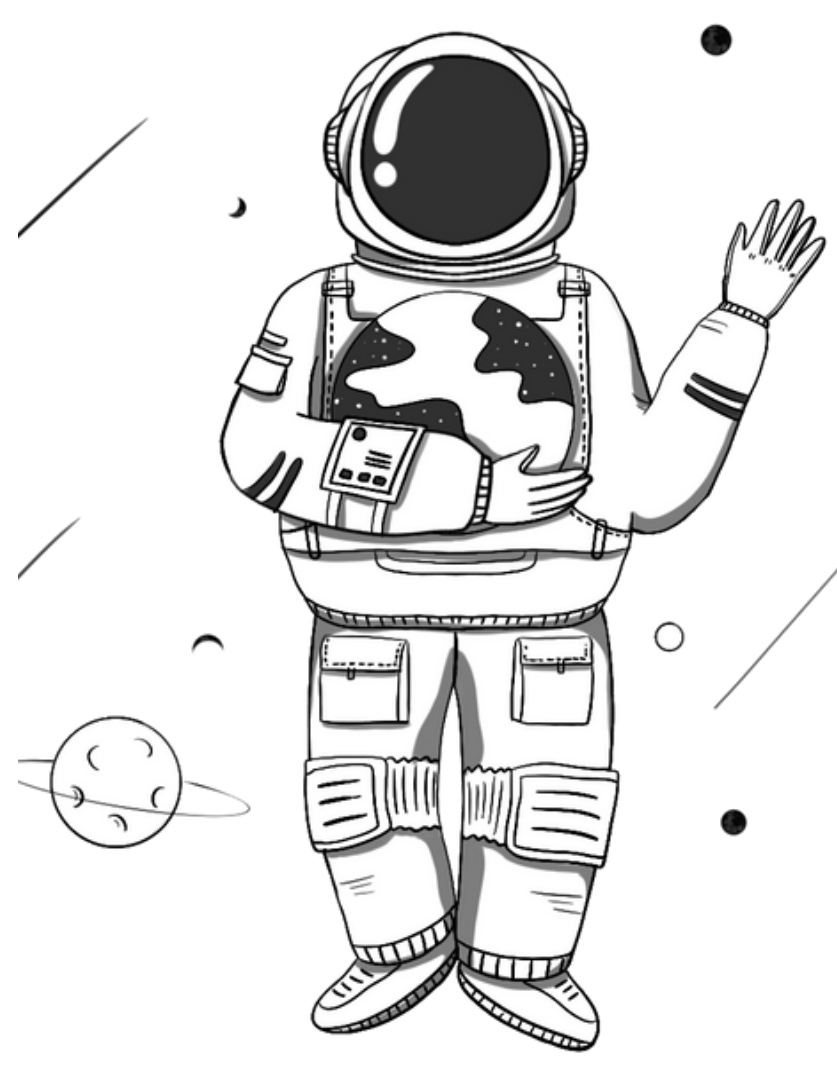




\section{De acordo com Brites (2018)}

A produção científica tem comprovado que o TDAH leva a alterações de funcionamento neurológico, problemas motores, atraso de desenvolvimento neuropsicomotor, disfunções cognitivas, prejuizos de rendimento no trabalho e nas atividades acadêmicas por levar a excessivo déficit atencional seletivo e sustentado, problemas de memória operacional, severas restriçóes na autoestima, risco maior de insucesso profissional, traumas, quedas e hospitalizações, desagregação familiar, separação conjugal e maior risco de suicídio

O TDAH tem sido muito estudado e discutido atualmente, pois é de suma importância que sejam divulgadas informações sobre o transtorno. Engana-se quem afirma que o TDAH é algo novo, ou "algo da moda", se baseando apenas no senso comum. O número de pesquisas científicas têm crescido nos últimos anos e pessoas com TDAH vem ilustrando essas pesquisas, demonstrando ganhos significativos na qualidade de vida, por terem sido identificadas e, portanto, recebido tratamento adequado. 


\section{DICA DE FILME!}

Por lugares incríveis (2020)

O filme, disponível na Netflix, é uma adaptação do livro de mesmo nome, de Jennifer Niven, que assina o roteiro em parceria com Liz Hannah. No decorrer da obra vamos percebendo características de TDAH no personagem Theodore Finch com seu pensamento acelerado, falta de controle sobre seus impulsos, falta de atenção nas aulas, impulsividade, além de sintomas sociais como poucos amigos e bullying por parte dos colegas de escola que o chamam de esquisito e "aberração", relembrando episódios em que ele perdeu o controle dentro do ambiente escolar.

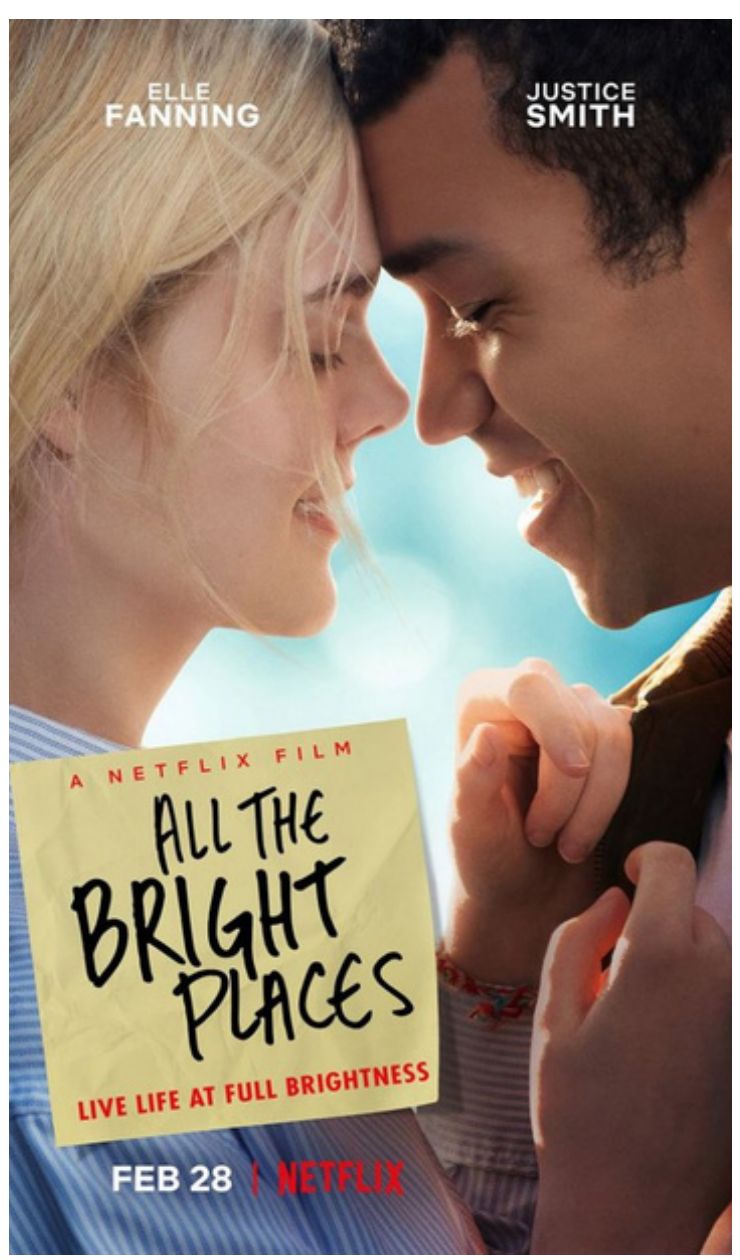

Com muita sensibilidade e cuidado, o filme propõe uma discussão sobre a saúde mental das novas gerações e a atenção que devemos dar aos sinais de sofrimento das crianças e adolescentes. O filme ainda nos deixa uma excelente reflexão sobre como podemos valorizar e desenvolver nossas capacidades, que são infinitas! 


\section{QUAIS SÃO AS CARACTERISTICAS DA PESSOA COM TDAH?}

Segundo Mattos (2015) os sintomas podem surgir quando a criança inicia sua vida escolar, porém, o autor ressalta que é necessário que esses sintomas estejam presentes antes dos 12 anos.

Para considerar que o indivíduo tenha TDAH, o DSM -V (2014) nos mostra os seguintes critérios diagnósticos, no que consiste um padrão persistente de desatenção e/ou hiperatividade-impulsividade que interfere no funcionamento e no desenvolvimento, conforme explicado a seguir:

DESATENÇÃO: Seis (ou mais) dos sintomas persistem por pelo menos seis meses em um grau que é inconsistente com o nível de desenvolvimento e têm impacto negativo diretamente nas atividades sociais $\mathrm{e}$ acadêmicas/profissionais.

É importante notificar que no caso de adolescentes ou adultos, são necessários apenas cinco destes sintomas:

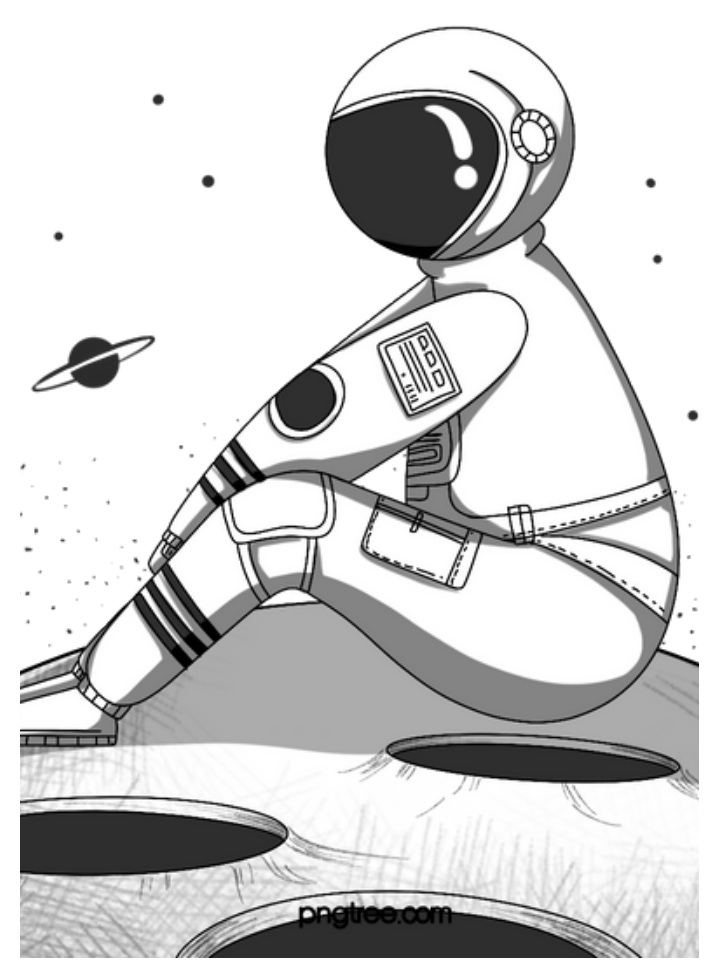


- Comete erros por descuido em tarefas escolares, no trabalho ou durante outras atividades ou não presta atenção em detalhes;

- Tem dificuldade de manter a atenção em tarefas ou atividades lúdicas; parece não escutar quando alguém dirige a palavra diretamente;

- Tem extrema dificuldade em seguir instruções até o final e não consegue terminar trabalhos escolares, tarefas ou deveres no local de trabalho;

- Tem dificuldade para organizar tarefas e atividades; evita, não gosta ou reluta em se envolver em tarefas que exijam esforço mental prolongado;

- Perde coisas necessárias para tarefas ou atividades; .

- É facilmente distraído por estímulos externos; é esquecido em relação a atividades cotidianas.

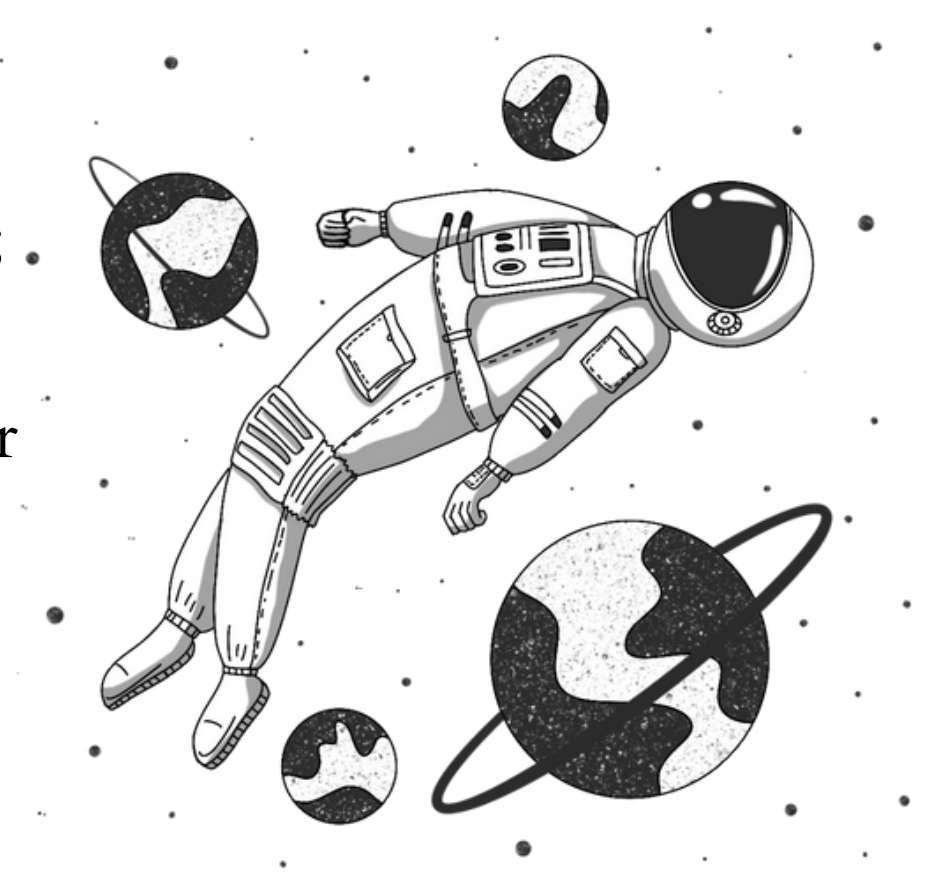


HIPERATIVIDADE E IMPULSIVIDADE: Seis (ou mais) dos sintomas persistem por pelo menos seis meses em um grau que é inconsistente com o nível do desenvolvimento e têm impacto negativo diretamente nas atividades sociais e acadêmicas/profissionais. Novamente, é importante notificar que no caso de adolescentes ou adultos, são necessários apenas cinco sintomas.

- Remexe ou batuca as mãos ou os pés ou se contorce na cadeira;

- Levanta da cadeira em situações em que se espera que permaneça sentado; corre ou sobe nas coisas em situações em que isso é inapropriado;

- É incapaz de brincar ou se envolver em atividades de lazer calmamente;

- Age como se tivesse com o "motor ligado", pois "não para”;

- Fala demais;

- Deixa escapar uma resposta antes que a pergunta seja concluída;

- Tem dificuldade para esperar a sua vez, pois interrompe ou se intromete.

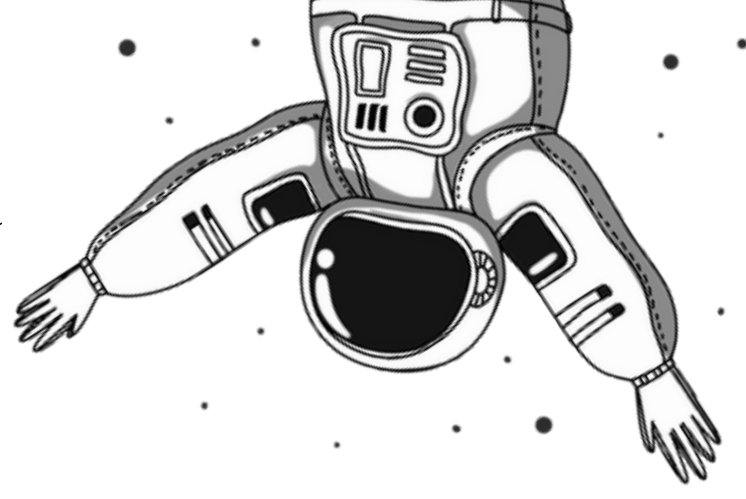




\section{É importante frisar que o TDAH possui três diferentes subtipos:}

\section{APRESENTAÇÃO COMBINADA: há tanto os}

critérios da desatenção quanto hiperatividade-impulsividade.

\section{APRESENTAÇÃO PREDOMINANTEMENTE}

DESATENTA: o critério da desatenção é preenchido, mas, a hiperatividade-impulsividade não.

\section{APRESENTAÇÃO PREDOMINANTEMENTE}

HIPERATIVA/IMPULSIVA: o critério de hiperatividadeimpulsividade é preenchido, mas, o critério da desatenção não.

Os subtipos devem ser apresentados durante os últimos 6 meses.

Quanto à gravidade do TDAH, o DSM - V informa que há quadros leves, moderados e graves. Em situações em que os indivíduos estão em supervisão, estão envolvidos em atividades de seu interesse, tem atenção personalizadas em ambientes individualizados, estão recebendo recompensas por ter bom comportamento ou mesmo recebendo estímulos, os sinais do TDAH podem ser vistos de intensidade menor ou até mesmo serem ausentes (DSM-V, 2014). 


\section{SUGESTÃO DE LEITURA}

Mitos e Verdades sobre o TDAH

Dr. Clay Brites

Neste e-book o neuropediatra Dr. Clay Brites apresenta os principais mitos que circundam o TDAH e as pessoas dentro do transtorno. No material, Brites esclarece que esta é uma condição médica e que seu intuito é desconstruir conceitos equivocados e muitas vezes sensacionalistas, que algumas pessoas tem sobre o TDAH.

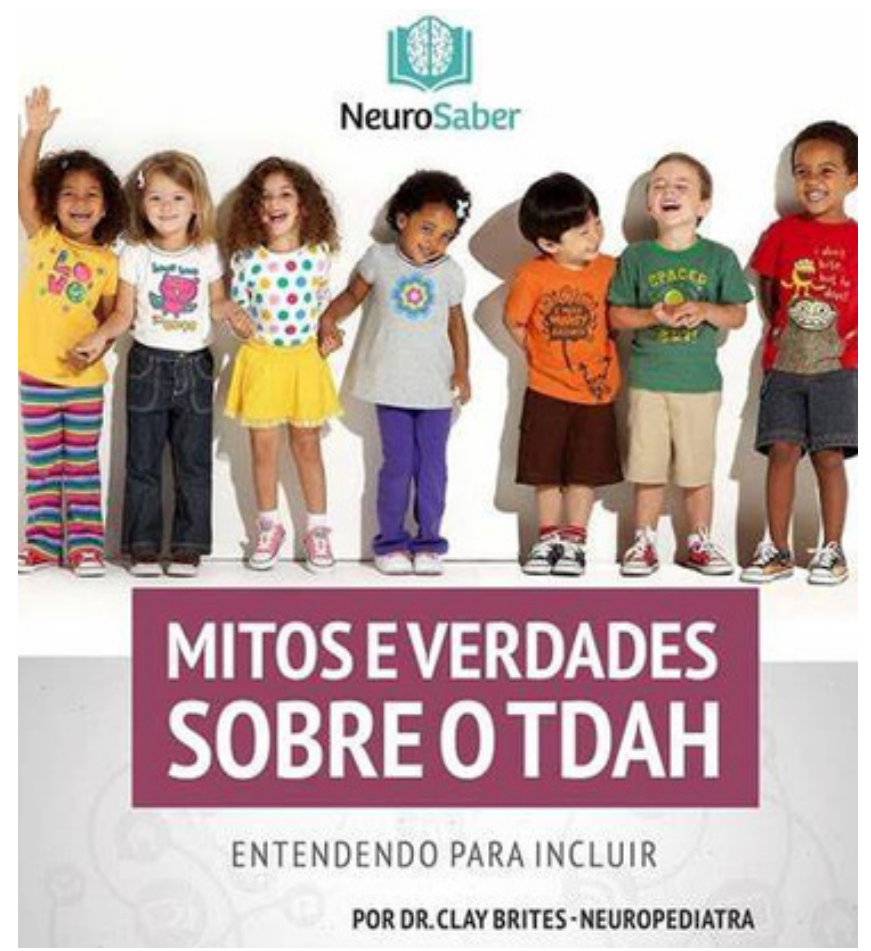

Com uma linguagem clara, coerente e muito pontual, o autor esclarece dúvidas e explica conceitos médicos, nos lembrando que já se foi a época em que nos baseávamos em tradições e mitos para definirmos uma rotina ou decidirmos sobre um tratamento. 


\section{QUEM PODE DIAGNOSTICAR \\ O TDAH?}

Para que o diagnóstico de TDAH seja concluído, é necessário um enfoque interdisciplinar, formado pelos profissionais de saúde, como: médicos, psicólogos, fonoaudiólogos, e também por profissionais da educação, como: psicopedagogos, pedagogos e professores. Por isso, é importante esclarecer que

não existe nenhum teste ou exame clínico que identifique esse transtorno (ABDA, 2017)

O relato do indivíduo é de extrema importância neste processo, pois fornece informações que levam a uma investigação minuciosa sobre si mesmo. Os pais e os responsáveis também adicionam informações primordiais para complementação do diagnóstico. 
Os professores podem perceber algumas características dentro da sala de aula, assim como os profissionais de saúde nas sessões de atendimento. Nesse momento, é importante que o profissional faça o encaminhamento para a avaliação interdisciplinar.

Entretanto, é importante frisar que somente os médicos das especialidades de psiquiatria, neuropsiquiatria, neuropediatria e neurologia são profissionais que prescrevem o diagnóstico final de TDAH.

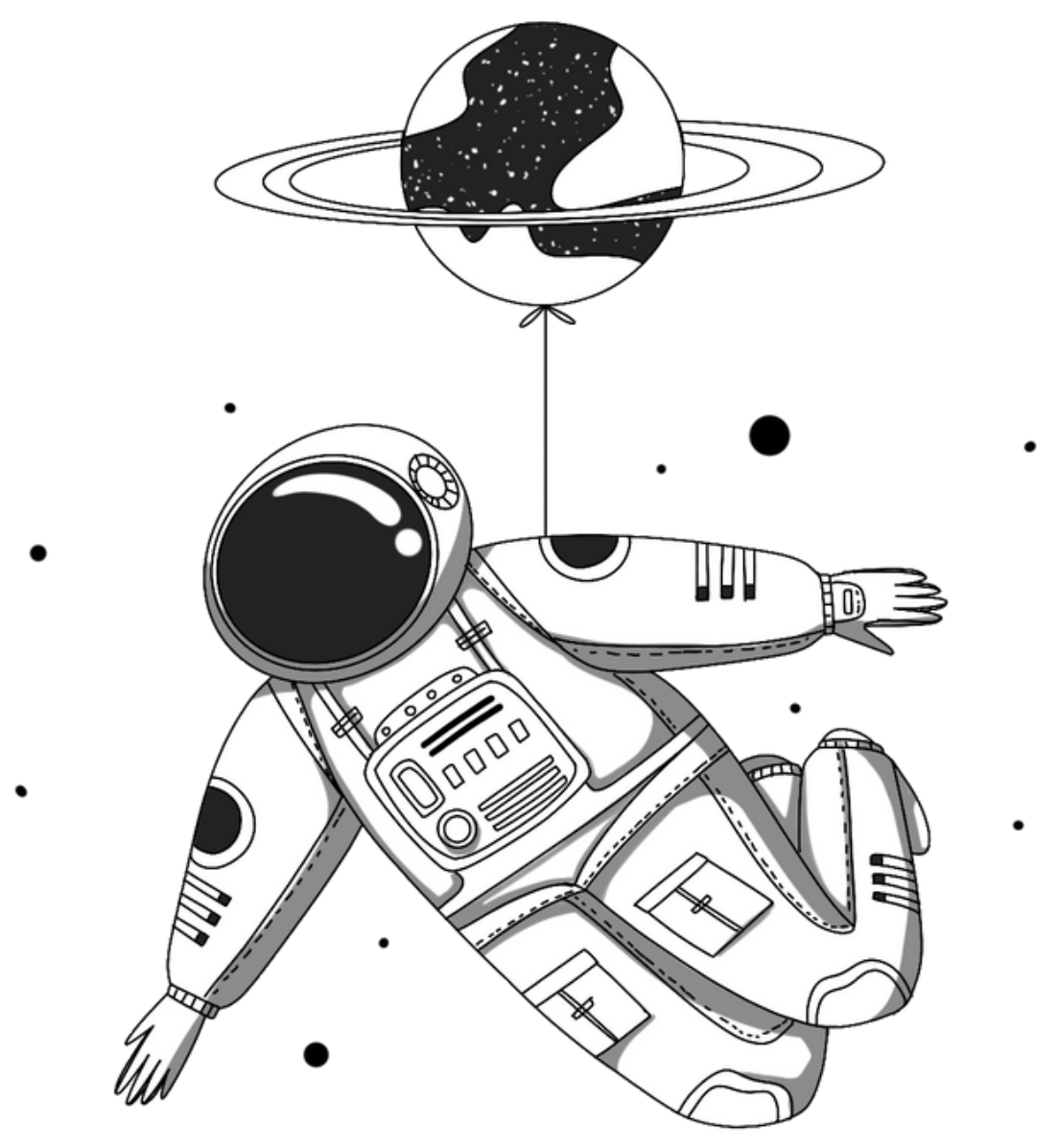




\section{SUGESTÃO DE LEITURA}

\section{No mundo da Lua}

Paulo Mattos

Essa é uma das obras mais populares sobre TDAH. Nela, o psiquiatra Paulo Mattos apresenta as principais características apresentadas por crianças, adolescentes e adultos que têm dificuldades em sustentar a atenção, manter o foco e concluir as tarefas. O título do livro é uma referência ao fato de muitas pessoas com TDAH ouvirem que estão "no mundo da lua", ou seja,

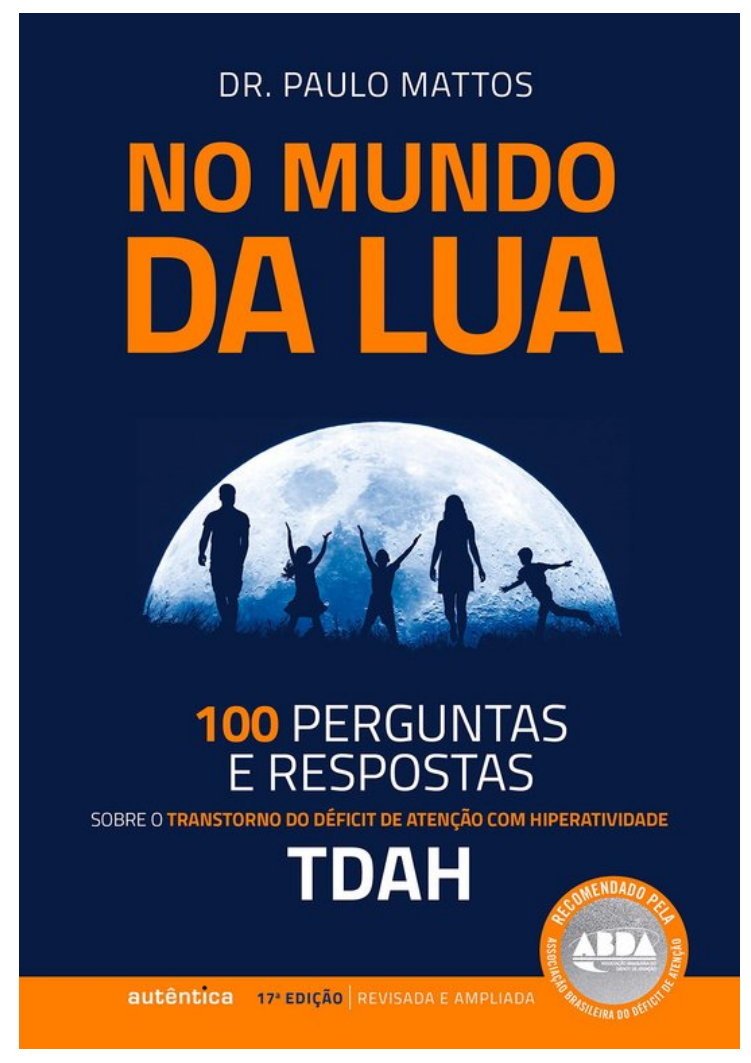

sempre parecem estar pensando em outra coisa ou em um monte de outras coisas ao mesmo tempo quando conversam com alguém, quando estudam, quando leem, quando trabalham, enfim, em uma grande variedade de situações do cotidiano. $O$ autor explica que na verdade o que ocorre é uma constante troca de interesses, ideias e planos que podem culminar em dificuldades em levar as coisas até o fim e descreve uma série de outras dificuldades que podem ocorrer na vida da pessoa com TDAH, mas que com apoio e acompanhamento adequados, podem superar inúmeros obstáculos. 


\section{COMO É REALIZADO O DIAGNÓSTICO DO TDAH?}

Muitas pessoas ao lerem a lista dos sintomas do TDAH se identificam imediatamente e acreditam serem portadoras de TDAH. E a partir daí, passam a "justificar" um grande número de coisas em suas vidas. Esse é um processo natural, uma tendência para que nosso cérebro tente encontrar explicações para todas as coisas. O "autodiagnóstico" frequente acontece justamente porque quase todo mundo tem alguns daqueles sintomas; isso não é o suficiente para o diagnóstico, entretanto." (MATTOS, 2015, p.50).

Como afirmamos anteriormente, até o presente momento não existe um teste ou exame clínico que por si só, conclua o diagnóstico de TDAH. Porém, eles podem detectar importantes indicativos. 
Segundo Rotta "o diagnóstico deve ter embasamento clínico em um composto de evidências derivadas da história, da observação, do exame clínico e neurológico e das escalas de comportamento" (ROTTA, 2016, p. 276). Ainda para a autora, esses sintomas precisam ocorrer em mais de um ambiente, seja escolar, familiar, de trabalho ou social.

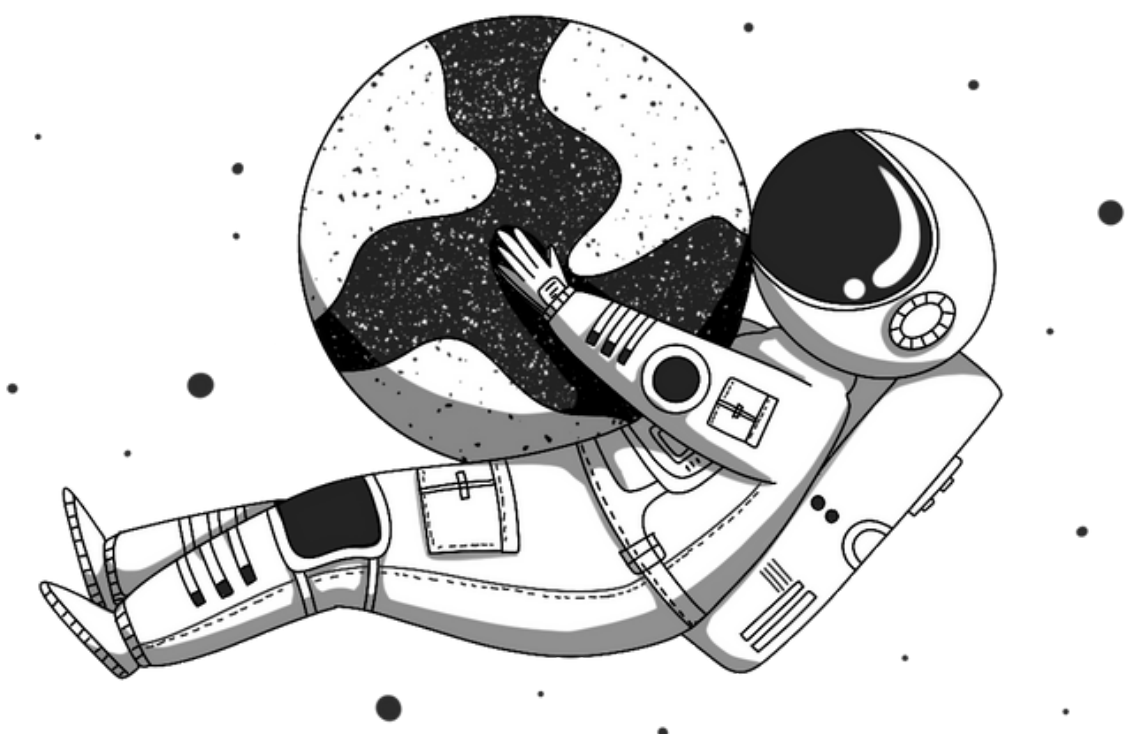

Assim, um dos primeiros passos da avaliação é realizar uma entrevista com o paciente e seus familiares/responsáveis, com o intuito de investigar as queixas atuais relativas à desatenção e hiperatividade. Nessa entrevista é importante abarcar o maior número de informações através de uma minuciosa investigação clínica da história do paciente, considerando que o TDAH é uma patologia com base genética.

A escola, através da equipe escolar, também pode fornecer informações essenciais para complemento da investigação do diagnóstico do TDAH. 
A Avaliação Multiprofissional com especialistas da área de Psicologia, Psicopedagogia e pedagogia é essencial para a identificação do transtorno. Esses profissionais deverão realizar um trabalho avaliativo com o objetivo de reconhecer os sintomas do TDAH através de testes clínicos ou psicométricos, anamnese realizada com a família, aplicação de questionários na escola e na família, além da observação do comportamento do paciente. Além disso, na aplicação dessas avaliações podem aparecer comorbidades significativas associadas.

O médico especialista é o profissional que prescreverá o diagnóstico conclusivo do TDAH, embora seja necessário que ele tenha aplicado as escalas de comportamento, recolhido as informações da história familiar do paciente retratado por seus familiares/responsáveis ou pelo próprio paciente, e, tenha ciência das informações dos outros profissionais descritas em seus relatórios, conforme frisado anteriormente. 
Depois de tê-lo feito, é possível realizar a psicoeducação do paciente e das pessoas que o rodeiam, realizar intervenções terapêuticas, indicar um tratamento adequado seja ele farmacológico ou não, construir uma ação educativa para sanar os problemas escolares, estabelecer estratégias pedagógicas adequadas e trabalhar para desenvolvê-los. Além disso, a avaliação precoce pode proteger esses indivíduos de alguns transtornos psiquiátricos na vida adulta, como por exemplo, a ansiedade e a depressão (ROTTA,2016).

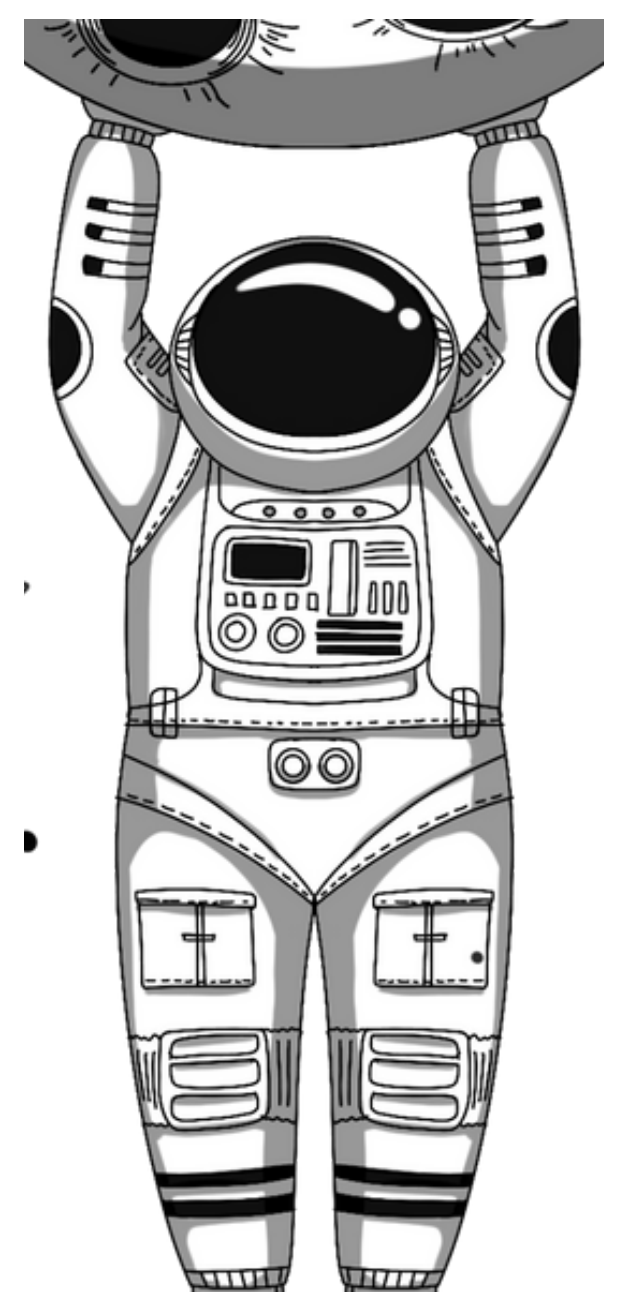

Torna-se importante informar que o TDAH não é uma doença, portanto, não existe uma cura, e sim, um tratamento para conviver com o transtorno, e para isso $\mathrm{O}$ conhecimento do diagnóstico tornase primordial, pois, quando não é realizado, os indivíduos podem ser rotulados de preguiçosos, "pessoas avoadas/voadoras", malcriadas, ou outros adjetivos. Logo, aos primeiros sintomas torna-se essencial fazê-lo, para evitar problemas futuros, consequentes desses rótulos 


\section{dica de documentárIO!}

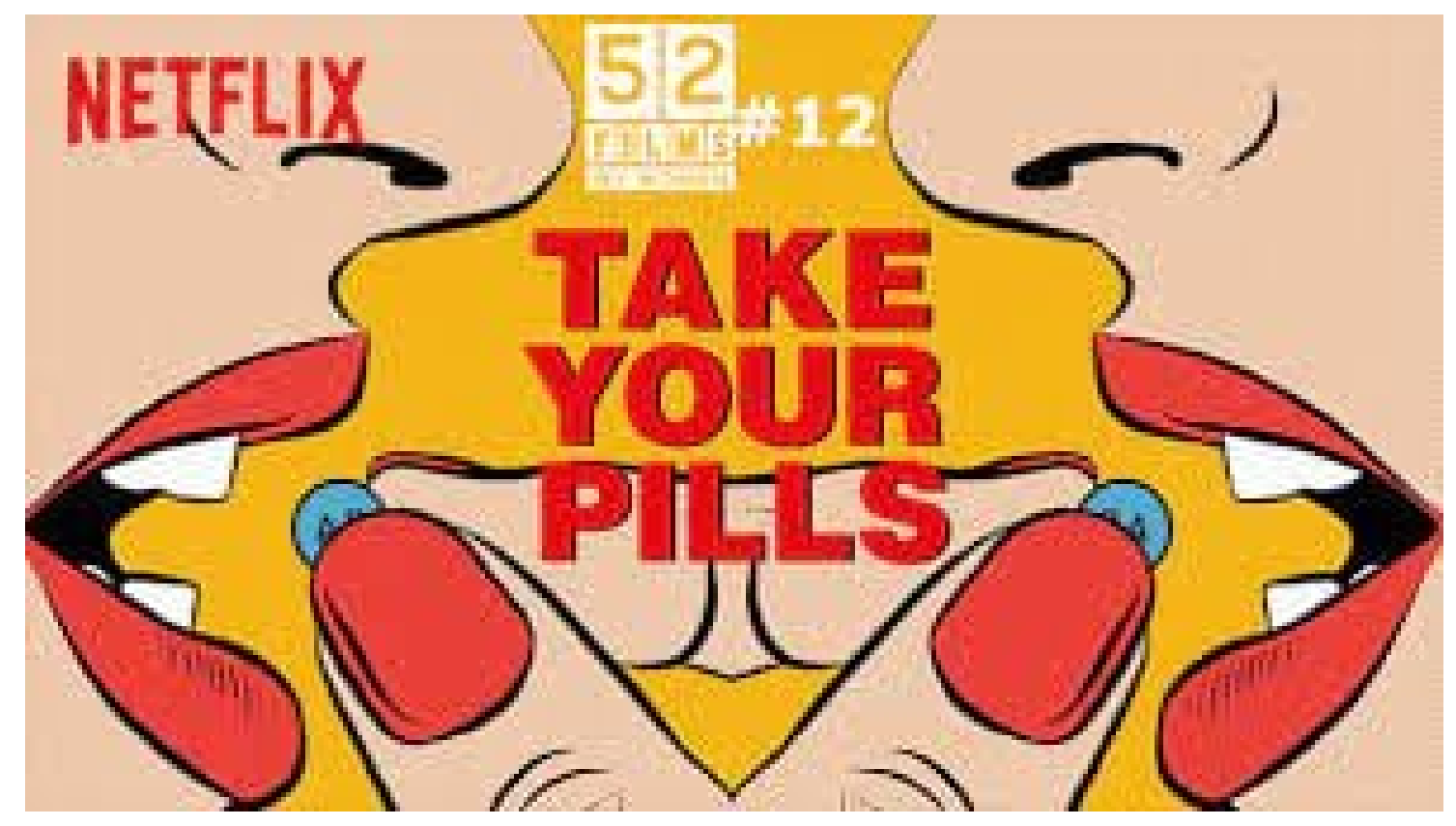

\section{Take your pills - 2018}

O documentário de 2018 Take your pills ou "Tome suas pílulas" em português, acompanha a vida de jovens que passam a tomar medicamentos como Adderall, Ritalina, Concerta entre outros, com o objetivo de melhorar sua concentração e seu desempenho. São apresentadas realidades de vários estudantes e profissionais e os efeitos que os medicamentos têm provocado em suas vidas. 


\section{QUAIS OS ATENDIMENTOS RECOMENDADOS PARA A PESSOA COM TDAH}

De forma geral, os atendimentos recomendados para a pessoa com TDAH dependem muito de quais são as suas características, suas necessidades e se há, ou não, outras condições associadas.

Dentre este leque de possibilidades, os mais recomendados são os acompanhamentos psicológicos voltados para a linha cognitivo comportamental em que serão trabalhados aspectos relacionados à conduta, manifestações e autocontrole, atendimento psicopedagógico, com o objetivo de recuperar possíveis déficits de conteúdos escolares, uma vez que o estudante com TDAH, devido à sua dificuldade de se concentrar por longos períodos, pode perder algum ou alguns conteúdos escolares necessários para seu desenvolvimento educacional. Em situações orientadas pelo profissional da saúde - médico neuropediatra, psiquiatra ou áreas afins, a intervenção medicamentosa também pode ser indicada. 
Sobre a medicação no tratamento, inúmeras pesquisas têm contribuído para esta discussão. Contudo, precisamos estar atentos para que a crença na intervenção do fármaco como solução, não reduza outras intervenções no trato pedagógico, que podem ser altamente funcionais e significativas.

De acordo com informações publicadas pelo Instituto Brasileiro de Defesa dos Usuários de Medicamentos (IDUM), em 2010 a venda do medicamento Ritalina aumentou $1.616 \%$ em relação ao ano 2000. No ano de 2010, foram consumidas aproximadamente dois milhões de caixas, colocando o Brasil como o segundo país que mais consome este medicamento no mundo. Para Mannoni,

(...) em vez de revolucionar o ensino e sua estrutura,

o ocidente prefere, pelo contrário, remediar os efeitos das anomalias geradas por um ensino inadequado à nossa época. Remediar os efeitos significa, neste caso, encarregar a medicina de responder onde o ensino fracassou

(MANFRE, 2018, p.09). 
Contudo, há casos em que a medicação se faz necessária e com acompanhamento médico, dosagem correta e continuidade dos atendimentos psicológicos e pedagógicos já indicados, podem auxiliar a pessoa com TDAH a melhorar sua qualidade de vida.

De acordo com o Dr. Clay Brites, na maior parte dos casos em que é recomendado o uso da medicação, tanto os pais quanto a escola veem a mesma coisa: a criança fica mais atenta e consegue dar conta das atividades que antes fracassava e reduzia sua autoestima.

O que reitera a importância de que cada caso seja acompanhado por uma equipe multiprofissional que avaliará os efeitos do uso fármaco nos diferentes espaços que a pessoa frequenta, considerando seu desempenho através de diversos aspectos.

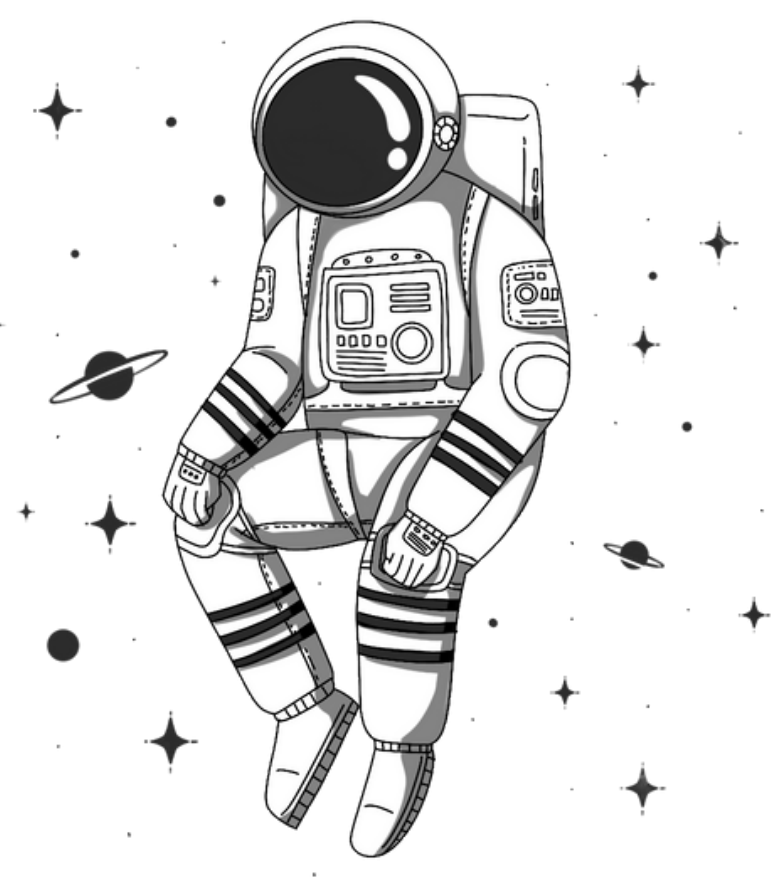




\section{SUGESTÃO DE LEITURA}

\section{Transtornos de Aprendizagem: Abordagem}

Neurobiológica e Multidisciplinar.

Newra Tellechea Rotta, Lygia Ohlweiler e Rudimar dos Santos Riesgo (ORGS)

Essa obra reúne profissionais da área da saúde e estudiosos de outras áreas para compartilhar seus conhecimentos e experiências sobre a prática diária, assim como, analisar de que maneira os transtornos interferem no aprendizado. Para tanto, o livro divide-se em três partes: Em Aprendizagem normal, são contempladas informações sobre dificuldades da aprendizagem relacionadas à escola, à família e aos aspectos físicos do próprio paciente.

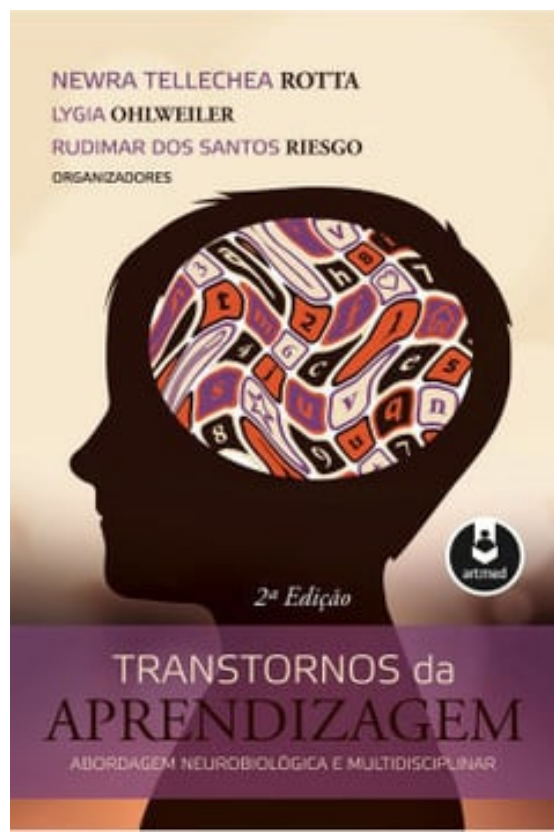

Em Transtornos da aprendizagem, são abordados problemas como dislexia, discalculia, dispraxias e transtornos da memória e da atenção. Nesta parte, foram incluídos três novos capítulos, os quais discutem aspectos neurobiológicos, clínicos e comorbidades dos transtornos do espectro do autismo. Em Aprendizagem e situações específicas, são analisadas as possíveis repercussões que epilepsia, paralisia cerebral, deficiência mental, autismo e problemas emocionais podem ter sobre o processo de aprendizagem. 


\section{A CRIANÇA COM TDAH É UM ESTUDANTE DE INCLUSÃO?}

De acordo com a LDB 9393/96 e com a mais significativa lei educacional de 2008, a Política Nacional de Educação Especial na perspectiva da Educação Inclusiva, observamos que os estudantes PAEE - público alvo da educação especial - são

os alunos com deficiência, transtornos globais de desenvolvimento e altas habilidades/superdotação *.

Assim, podemos perceber que os estudantes com TDAH, necessariamente, não são incorporados ao grupo do PAEE, considerando que este é definido dentre os transtornos funcionais específicos. No entanto, como percebemos até aqui, os estudantes com TDAH podem apresentar diversas fragilidades em seu desempenho escolar, tendo em vista suas dificuldades de se manter concentrado por um longo período de tempo, se distrair com facilidade, não conseguir se manter dentro do comportamento desejado e, em consequência, apresentar um rendimento educacional abaixo do esperado 
Neste sentido, a LDB 9394/96 vem ao encontro dessas necessidades quando afirma que

Art.12 - Os estabelecimentos de ensino, respeitadas as normas comuns e os do seu sistema de ensino, terão a incumbência de:

I - Elaborar e executar sua Proposta Pedagógica; (...)

V - Prover meios para a recuperação para os alunos de menor rendimento;

Art.13 - Os docentes incumbir-se-ão de:

III - Zelar pela aprendizagem dos alunos;

IV - Estabelecer estratégias de recuperação para os alunos de menor rendimento (BRASIL, 1996).

Logo, podemos perceber que os estudantes com TDAH precisam ser incluídos em estratégias diferenciadas de ensino e avaliação que contemplem o acompanhamento de seu desenvolvimento escolar, ao mesmo tempo em que respeitam suas especificidades 
Neste sentido, a reflexão que gostaríamos de provocar aqui, é a respeito da amplitude que caracteriza a temática, questionando por que muitos profissionais, incluindo os professores, após suspeitar que uma criança tem TDAH, necessitam de um diagnóstico clínico para iniciar suas intervenções?

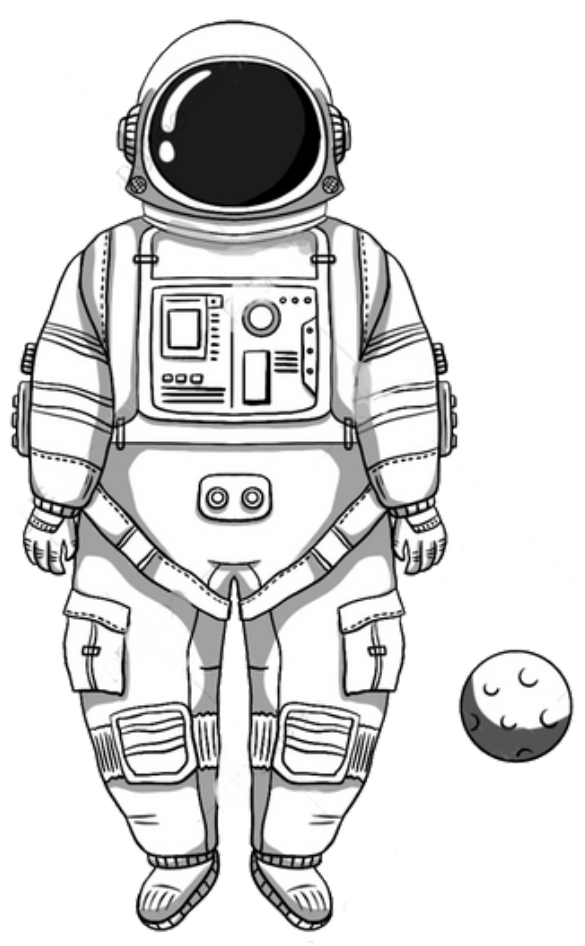

Defendemos a avaliação e o processo correto de diagnóstico, mas, o que questionamos é que muitas vezes o que está sendo tratado como patológico pode ser a manifestação de um pensamento sufocado e neutralizado pela instrumentalidade científica e pelo estabelecimento de condutas esperadas que não correspondem ao perfil de todos os estudantes. Em outras palavras, o estudante ao expressar sua defensiva à experiência opressora dos modos de existir no espaço escolar, acaba sendo rotulado e patologizado, ao tempo em que, se fosse realizado um trabalho academicamente significativo e dinâmico, talvez muitas de suas inquietações fossem transformadas em objetos de investigação, pesquisa e desenvolvimento do seu potencial. 
Reforçando esta perspectiva, Carvalho ressalta que uma escola inclusiva implica em mudança de atitude diante das diferenças individuais com vista à efetivação do trabalho na diversidade e com o propósito de remover todos os tipos de barreiras que impedem o acesso à aprendizagem e à participação plena da vida em sociedade (CARVALHO, 2004).

Neste sentido, não podemos culpar apenas os estudantes por seu fracasso escolar. Antes, é preciso rever conceitos, metodologias, estratégias e processos avaliativos para que tenham como objetivo acompanhar seu desenvolvimento sem o caráter punitivo e classificatório, tão tradicionalmente percebido em muitas escolas.

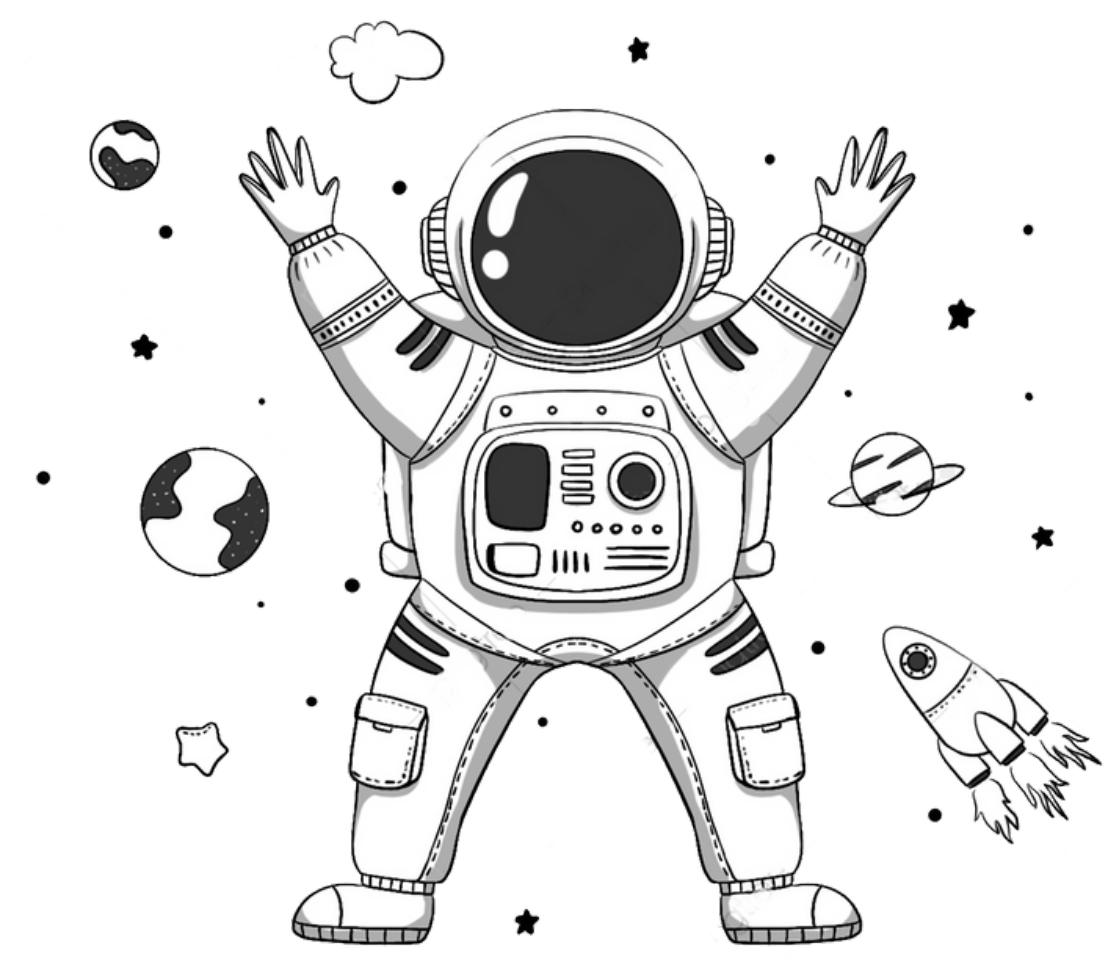




\section{DICA DE FILME}

\section{FILME: O SOM DO CORAÇÃO - 2007}

É um drama dirigido por Kristen Sheridan e escrito por Nick Castle, James V. Hart, Kirsten Sheridan e Paul Castro, e produzido por Richard Barton Lewis. $\mathrm{O}$ menino Evan (Freddie Highmore) mora em um orfanato. Neste lugar, ele tem a ideia de viajar para Nova York na busca de seus pais biológicos, através de sua música.

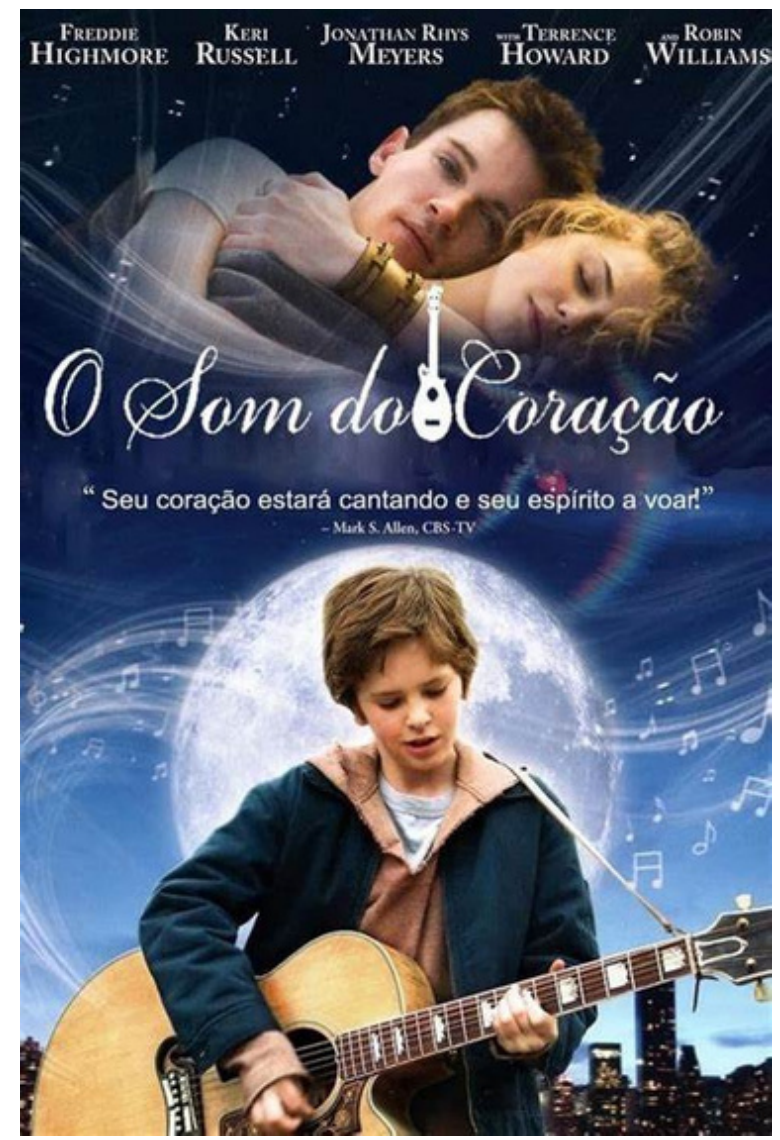

Durante sua procura, ele conhece Wizard (Robin Williams), que descobre as habilidades musicais do garoto, e o batiza de August Rush. Ao mesmo tempo, seus pais, que são músicos, procuram por ele também. No filme, é possível identificar que o garoto August apresenta alguns sintomas do TDAH, além de promover uma reflexão sobre persistência, amor e luta pelo seu sonho. 


\section{O TDAH PODE ESTAR ASSOCIADO A OUTROS TRANSTORNOS?}

Inicialmente, vamos considerar uma breve explicação sobre comorbidade. Esse nome é um termo técnico usado na área da saúde, para indicar uma associação de duas ou mais condições/ doenças que surgem ao mesmo tempo, em uma única pessoa. Também podem ser usados os termos dupla condição ou dupla excepcionalidade.

"Estima-se que 50\% das crianças com TDAH apresentam comorbidade com outras psicopatologias, e que esta comorbidade tende a aumentar conforme o tempo. Os tipos de comorbidades registrados pela literatura variam dependendo da idade, do sexo e da fonte de onde sejam obtidos" (CONDERMARIN et al, 2006, p.102).

Algumas comorbidades que podem estar associadas ao TDAH são: transtornos de aprendizagem, transtorno de linguagem, transtorno opositor desafiador - TOD, transtorno de ansiedade, transtorno de humor ou transtorno de tiques. 
Concomitante, podem ocorrer outros transtornos da aprendizagem, bem como desordens psicopatológicas e emocionais, sendo que, usualmente, o TDAH está associado com a dislexia, discalculia e disgrafia (sendo considerados também comorbidades) pois o TDAH se caracteriza por alterações nos sistemas motores, perceptivos, cognitivos e do comportamento.

Isso tudo compromete o desenvolvimento e a aprendizagem da criança que tem potencial intelectual dentro da média (GUARDIOLA, 2016; ROTTA, 2016), mas, por conta destas características o indivíduo com TDAH pode apresentar maus resultados escolares, então é importante ter clareza do diagnóstico e da consequente proposta de métodos eficazes de intervenção.

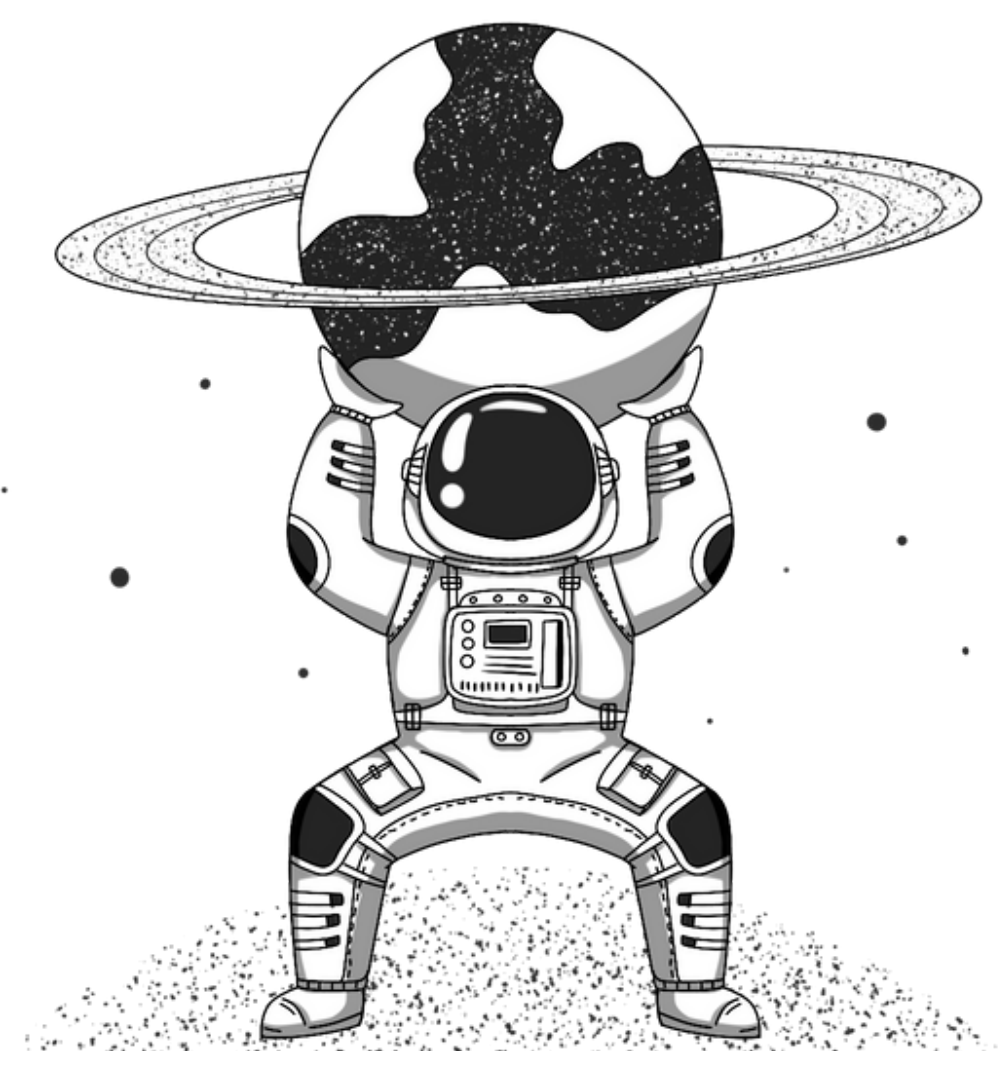




\section{TDAH E COMORBIDADES}

\begin{tabular}{|c|c|}
\hline $\begin{array}{l}\text { Transtorno de } \\
\text { Aprendizagem }\end{array}$ & $\begin{array}{l}\text { Podem apresentar transtornos } \\
\text { específicos, como: dislexia, disgrafia e } \\
\text { discalculia, sendo a dislexia, a } \\
\text { comorbidade mais frequente. }\end{array}$ \\
\hline $\begin{array}{l}\text { Transtorno da } \\
\text { linguagem }\end{array}$ & $\begin{array}{l}\text { Esse transtorno está presente, seja por } \\
\text { distúrbios da fala, como dificuldades } \\
\text { articulatórias, alteração do ritmo da fala } \\
\text { e da qualidade de vocalização, seja por } \\
\text { distúrbios da linguagem, tanto na } \\
\text { percepção quanto na elaboração, como } \\
\text { falhas no acesso lexical, dificuldades de } \\
\text { estruturação sintático-semânticas e } \\
\text { falhas no processamento da informação. }\end{array}$ \\
\hline $\begin{array}{l}\text { Transtorno } \\
\text { opositor } \\
\text { desafiante } \\
\text { (TOD) } \\
\text { e } \\
\text { Transtorno de } \\
\text { Conduta (TC) }\end{array}$ & $\begin{array}{l}\text { Apresentam o TOD, associado ao humor } \\
\text { instável, enfrentar e desobedecer às figuras } \\
\text { de autoridade, ter irritabilidade fácil, } \\
\text { podendo chegar a acessos de raiva } \\
\text { incontroláveis. } \\
\text { Quando o comportamento é antissocial, } \\
\text { configurando o TC, apresenta a falta de } \\
\text { respeito às regras sociais, fugas, atos cruéis, } \\
\text { podendo incluir até mesmo, abusos sexuais. }\end{array}$ \\
\hline
\end{tabular}




\section{Transtorno de Ansiedade}

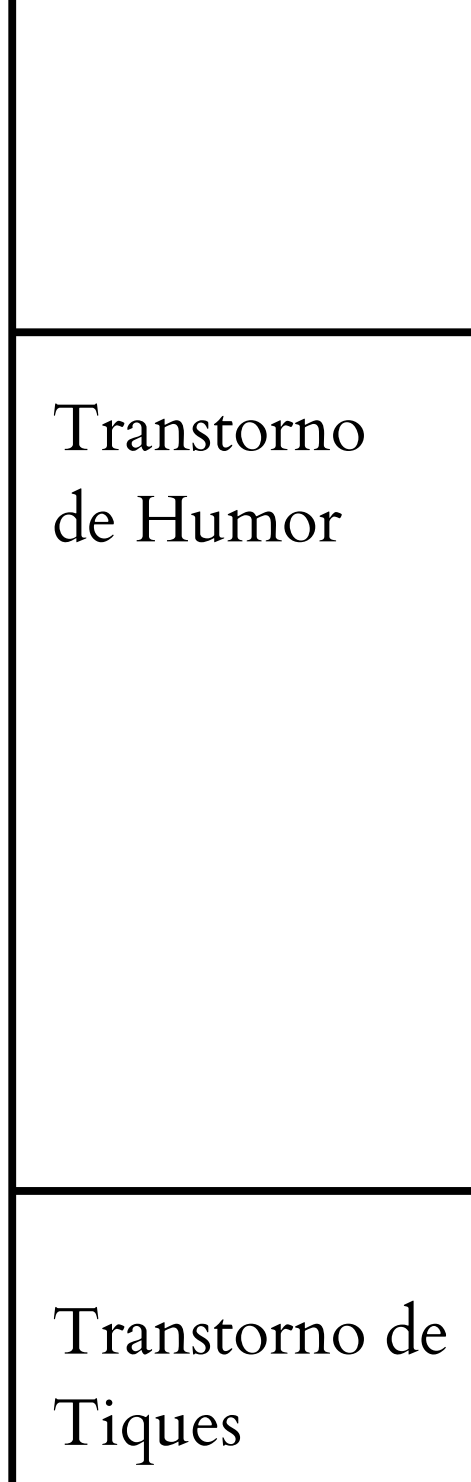

Fonte: Adaptado de Rotta (2016) 
Mattos (2015) comenta que ao entrar na adolescência, os indivíduos com TDAH podem apresentar maior risco para o uso excessivo de álcool e de drogas ilícitas, além dos comportamentos irresponsáveis, muitas vezes originados pela impulsividade.

Ressalta-se que um indivíduo que apresente depressão e ansiedade pode ter uma atenção reduzida, dificuldades de memória, aumento da atividade motora e desconcentração, o que pode ser confundido com alguns critérios diagnósticos de TDAH (ANTONY, 2018).

É importante informar que nem todos os indivíduos com TDAH apresentam comorbidade com outros transtornos, porém, identificar os possíveis quadros são fundamentais para o diagnóstico, já que afeta a expressão dos sintomas, o prognóstico e o tratamento (CONDERMARIN et al, 2006).

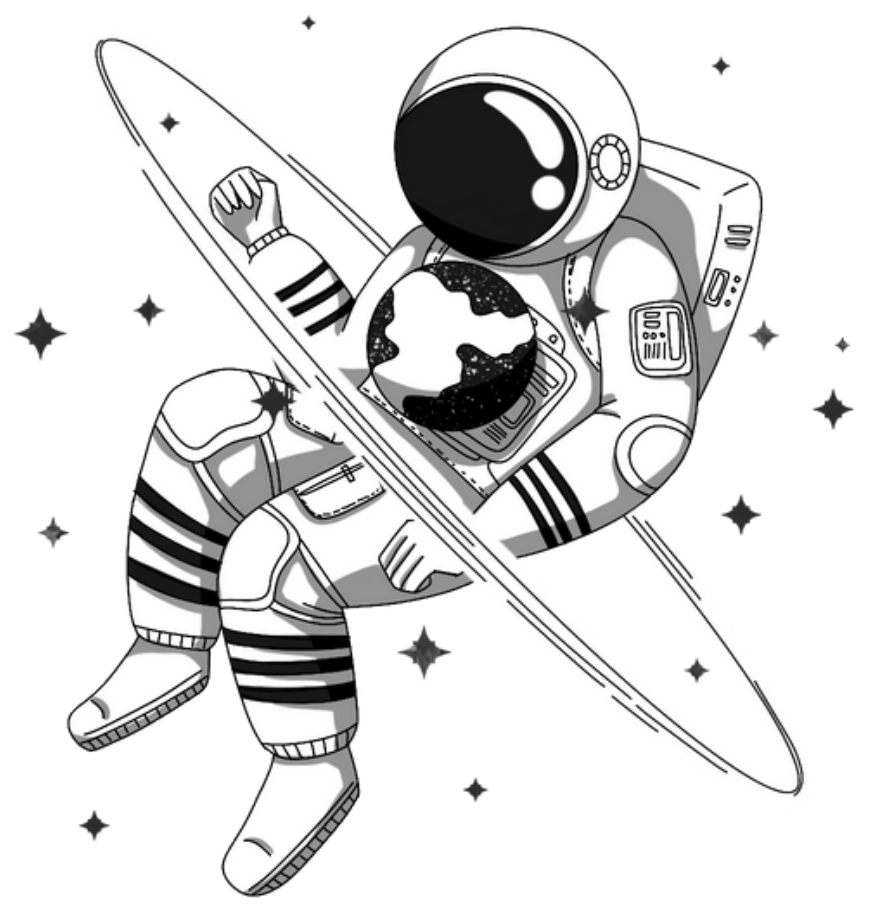




\section{SUGESTÃO DE LEITURA}

Transtorno do Déficit de Atenção: estratégias para

o diagnóstico e a intervenção psico-educativa.

Mabel Condemarín - María Elena Gorostegui -

Neva Milicic

Este livro direciona caminhos para as crianças que têm o diagnóstico de TDAH proporcionando uma melhor qualidade de vida em todos os ambientes que ela possa transitar, e em paralelo, se ajustar no meio da sociedade, de forma a serem compreendidas e serem mais felizes em seu caminhar. Os autores, de forma simples e objetiva, ensinam esses caminhos com uma linguagem de fácil entendimento sobre o

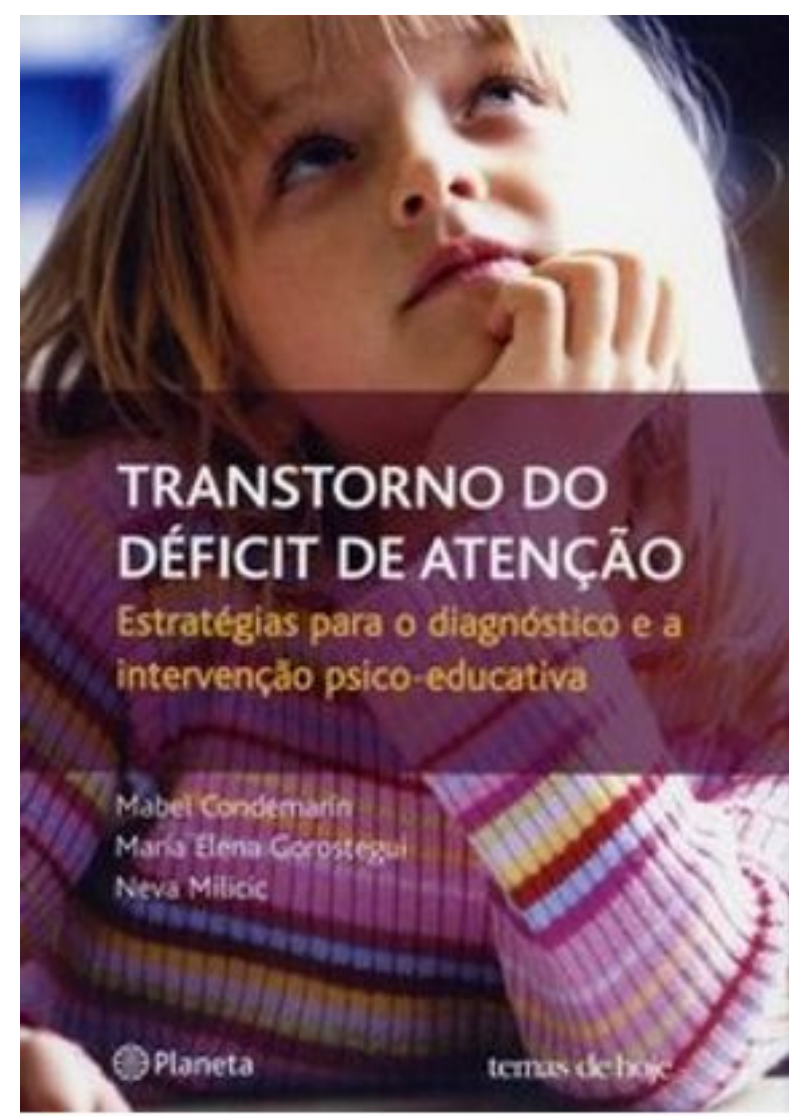
TDAH. 


\section{QUAL A IMPORTÂNCIA DA FAMÍLIA PARA O DESENVOLVIMENTO DA PESSOA COM TDAH?}

Dentro do ambiente familiar, é bastante comum ouvir que esse indivíduo não escuta o que os outros indivíduos falam, não segue regras e normas, não consegue completar tarefas simples, age com agressividade e são considerados pela família como aquele indivíduo inoportuno, desobediente, preguiçoso, mal educado, e, assim, "o excesso de atividade motora, o alto nível de impulsividade evidenciada na antecipação das respostas e na inabilidade para esperar a sua vez, diante de um acontecimento, pode provocar, geralmente, um impacto negativo nas relações sociais e ou familiares e promover um alto nível de estresse com quem convive com esse indivíduo" (BENCZIC; CASELLA, 2015, p.96).

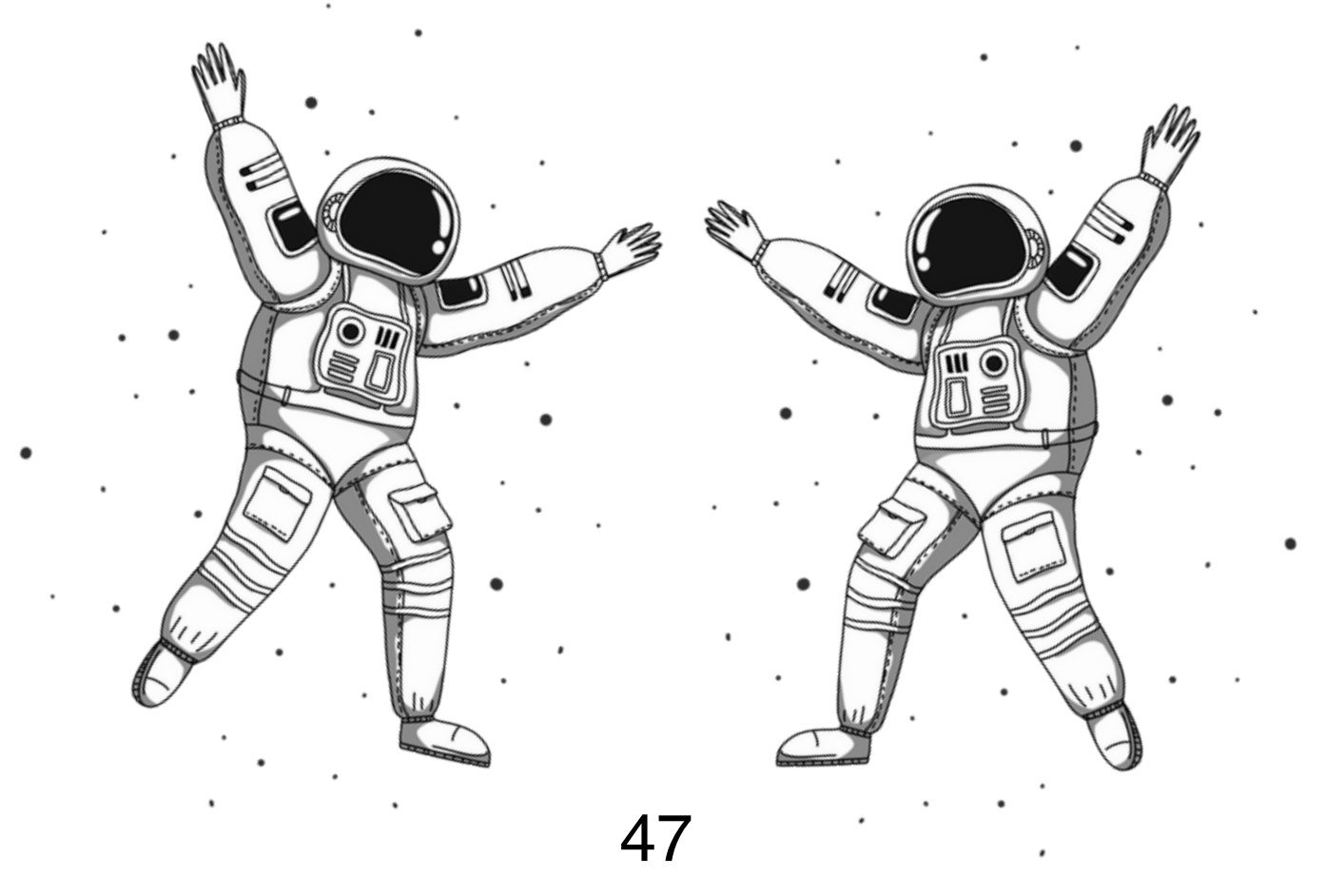


Esses conflitos que surgem no ambiente familiar, pode ser visto no relacionamento com os pais, com seus irmãos e também em integrantes de outras famílias. Alguns comportamentos tendem a acontecer com mais frequência, como: eles argumentam mais, eles gritam mais com seus irmãos, eles são mais propensos a apresentar um comportamento inapropriado. Como consequência, esse indivíduo requererá maior tempo de atenção que seus irmãos, por exemplo, e pode provocar sentimentos de ciúme ou inveja entre os membros da família (BENCZIC; CASELLA, 2015).

Assim, quando o indivíduo é diagnosticado com TDAH, a família tem papel fundamental nesse processo, principalmente para acolher e apoiar. Torna-se necessário que os pais/responsáveis ou o próprio indivíduo busque informações sobre o transtorno, abarcando os sintomas, as causas e os tratamentos. Para isso, é importante pesquisar em sites especializados, procurar livros especializados, fundamentação científica e ter profissionais especialistas para realizar uma psicoeducação com a finalidade de compreender melhor sobre seus comportamentos e saber a melhor maneira de conduzi-los. 
Segundo Mattos (2015) é fundamental para a família que o diagnóstico de TDAH seja compreendido com um problema real e que requer alguns cuidados especiais. $\mathrm{O}$ autor aponta alguns manejos que podem ser realizados no ambiente familiar, como: manter diálogos sobre os problemas em casa, ajudar o indivíduo a entender suas próprias dificuldades, escutar sobre o comportamento que facilita ou dificulta as coisas, estimulá-lo a formar opiniões e a discutir sobre elas, estabelecer normas claramente e objetivas, construir rotinas no ambiente que seja previsível onde o indivíduo possa saber exatamente o que se espera dele, focar nos comportamentos positivos, falar sempre olhando para ele, evitar explicações longas e detalhamento excessivo, ensinar técnicas de estudos como resumir o que leu em voz alta, fazer resumos escritos, usar canetas coloridas para ressaltar as partes mais importantes, fazer um calendário para anotar tarefas importantes e outras que julgar necessárias para melhor condução dos objetivos nos ambientes acadêmico e social. 


\section{UM ADULTO PODE TER TDAH?}

O diagnóstico também pode ser feito após a maior idade, tendo em vista que as dificuldades interpessoais, de concentração e atenção podem persistir também nesta fase. Contudo, o critério de idade de início dos sintomas, o ponto de corte de seis sintomas e a necessidade de atestar comprometimento funcional em ao menos dois ambientes distintos, são algumas das principais dificuldades encontradas na prática clínica para o estabelecimento do diagnóstico em adultos que frequentemente apresentam dificuldades para resgatar informações remontando à infância (DIAS et al., 2007).

Ainda para os autores, ao contrário da avaliação de TDAH em jovens, na qual relatos de pais e professores são de extrema importância, a avaliação em adultos é baseada primordialmente no autorrelato (DIAS et al, 2007). Descuido nas atividades, falta de organização, dificuldade em manter a concentração e a atenção, inquietude e hiperatividade são apenas alguns dos sintomas típicos do adulto com TDAH. 
É importante destacar que avaliação em adultos é um tema bastante discutido por pesquisadores da área, levando em conta que os testes são adaptados das escalas utilizadas com crianças. Neste sentido, existem algumas dificuldades na avaliação do comprometimento provocado por um sintoma, uma vez que a disfunção pode não ocorrer no mesmo nível em todos os contextos ou no mesmo contexto em todos os momentos (DIAS et al, 2007).

Além disso, na vida adulta é comum que os sintomas variem de gravidade de acordo com as demandas ambientais. Os sintomas pioram em situações que demandam atenção, concentração ou que sejam desinteressantes para o indivíduo.

É importante considerar que pessoas sem a condição também podem apresentar alguma desatenção e inquietude em situações tediosas, porém, no TDAH, os sintomas são mais expressivos e podem ocorrer mesmo em situações de lazer. Assim, se você já está na fase adulta e se incomoda com sua desorganização ou dificuldade de concentração e planejamento, por exemplo, busque uma equipe multidisciplinar especializada na avaliação de adultos com TDAH. É somente através da avaliação que estas questões serão investigadas identificando a intensidade dos sintomas e verificando se eles se encaixam na condição, com características específicas na vida adulta. 


\section{CARACTERÍSTICAS OBSERVÁVEIS NA VIDA ADULTA}

- Impulsividade

- Agitação

- Impaciência

- Inquietude

- Desatenção

- Falta de memória - incapacidade de se lembrar de pequenos pedidos ou de cumprir com tarefas domiciliares como pagar contas e desligar eletrodomésticos

- Esquecimento de nomes e fatos

- Enjoa rapidamente do que é novidade

- Dificuldades em cumprir horários

- Problemas com a proatividade, necessitando sempre de estímulos ou do chamado "empurrãozinho

- Dificuldades em se concentrar e captar as informações em longas reuniões de trabalho ou palestras

- Problemas com a chamada manutenção do esforço - aos poucos vai perdendo a vontade e o "gás" para concluir aquilo que começou

- Problemas para controlar suas emoções: pode ser muito impaciente e se frustrar com facilidade nos relacionamentos 


\section{Quais os desafios da pessoa com TDAH na sociedade?}

Como podemos observar até aqui, existem possibilidades de sucesso e dificuldades na vida escolar e na fase adulta da pessoa com TDAH.

Obviamente, não temos a pretensão de premeditar uma lista de dificuldades que poderão ser enfrentadas, considerando que estes desafios podem variar muito de acordo o momento em que a avaliação foi realizada (se foi precoce ou tardia) e os encaminhamentos e acompanhamentos realizados desde este período.

Tendo em vista esta premissa, organizamos algumas sugestões que podem auxiliar a pessoa com TDAH a ter uma vida com menos cobranças e conflitos, considerando que, por mais difícil que possa inicialmente parecer conviver com este transtorno, com respeito às suas características e com o acolhimento de suas dificuldades, é sim possível ter amigos, emprego, relacionamentos e uma vida socialmente ativa! 
- Uma das características das pessoas com TDAH é o fato de esquecer compromissos, perder as chaves, esquecer de atribuições corriqueiras como pagar as contas, abastecer a geladeira, entre outros. Estabeleça uma rotina, atualmente é possível programar a agenda no celular, o que facilita muito a organização dessas obrigações.

- Para que o agendamento das atividades funcione, evite a procrastinação e faça o que tiver que ser feito na hora. Tarefas como responder a um e-mail importante, pagar contas, retornar uma ligação, ou preparar uma apresentação de entrevista de trabalho, por exemplo, devem ser feitas de acordo com a sua programação, pois de nada adiantará programar uma atividade se você não executar. E lembre-se de executar uma tarefa de cada vez para não se perder no meio delas.

- Como as pessoas com TDAH tem um funcionamento cerebral acelerado, procure evitar o consumo de cafeína e o contato com telas e estimulantes durante a noite para conseguir dormir bem. Isso faz toda a diferença no dia seguinte!

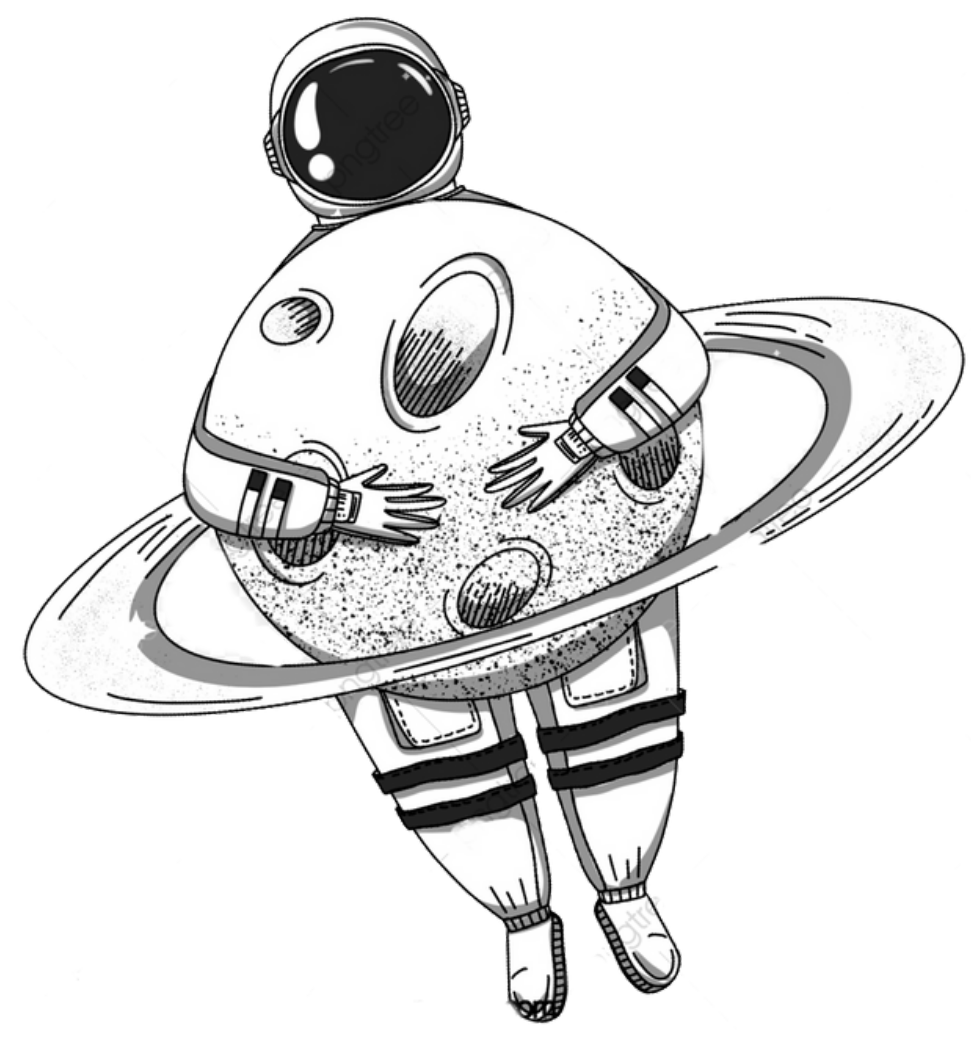


- Pratique exercícios físicos com regularidade. Não precisa necessariamente fazer musculação em uma academia, mas procure realizar um esporte ou atividade que você goste e que lhe façam se sentir bem. Ioga e meditação também são fortemente recomendados por buscarem a calma, o equilíbrio e a concentração.

- Estabeleça uma prioridade diária e organize seu tempo. Se você mantiver uma rotina básica, ficará muito mais fácil inserir os demais compromissos quando eles surgirem. Também é importante não ser impulsivo e aprender a dizer não em alguns momentos. Assim, você não se sobrecarrega, respeita os seus limites e se mantém sempre responsável por seus compromissos assumidos.

Além dessas dicas para enfrentar os desafios, é muito importante lembrar que, quanto mais precocemente o diagnóstico for realizado e mais cedo as intervenções forem iniciadas, maiores são as chances de regularização do comportamento e da atenção, o que proporcionará a pessoa com TDAH uma melhora significativa em suas relações interpessoais, familiares e profissionais. 


\section{REFERÊNCIAS:}

AMERICAN PSYCHIATRIC ASSOCIATION - APA. Manual diagnóstico e estatístico de transtornos mentais: DSM-5. Porto Alegre: Artmed, 2014.

BRASIL. Lei n. ${ }^{\circ}$ 9.394, de 20 de Dezembro de 1996. Estabelece as diretrizes e Bases da educação nacional. Disponível em: <http://www.planalto.gov.br/CCIVIL_03/leis/L9394.htm>. Acesso em: maio/2021.

Política Nacional de Educação Especial na Perspectiva da Educação Inclusiva, Ministério da Educação. Secretaria de Educação Especial. Brasília: MEC/SEESP, 2008.

BENCZIK, E. B. P.i; CASELLA, E. B.. Compreendendo o impacto do TDAH na dinâmica familiar e as possibilidades de intervenção. Rev. psicopedag., São Paulo, v. 32, n. 97, p. 93-103, 2015 . Disponível em <http://pepsic.bvsalud.org/scielo.php?script=sci_arttext\&pid=S0103$84862015000100010 \& \operatorname{lng}=$ pt\&nrm=iso>. acessos em 02 jun. 2021.

CARVALHO, R. E. Educação Inclusiva: com os pingos nos "is". Porto Alegre: Mediação, 2004.

CONDEMARIN, M.; GOROSTEGUI, M.; MILICIC, N. Transtorno do Déficit de Atenção: Estratégias para o diagnóstico e a intervenção psico-educativa. São Paulo: Planeta, 2006.

DIAS, G.; SEGENREICH, D.; NAZAR, B.; COUTINHO, G.; Diagnosticando o TDAH em adultos na prática clínica. J. Bras. Psiquiatria. 56, supl 1; p. 9-13, 2007.

GOMES, N. A.; GABRIEL, K. M.; MAESTRI, M. Caracterização neuropsicológica do Transtorno de Déficit de Atenção/Hiperatividade (TDAH) na vida do adulto. Psicologia: um olhar do mundo real. Volume 2, 20217.

LURIA, A. R. Fundamentos de Neuropsicologia. São Paulo: Livros técnicos e científicos S.A., 1981.

MATTOS, P. No mundo da lua: perguntas e respostas sobre transtorno do déficit de atenção com hiperatividade em crianças, adolescentes e adultos. São Paulo: Lemos Editorial, 2015.

MANFRE, Ademir Henrique. Está me chamando de doente? O discurso medicalizante do TDAH na escola: uma revisão. Rev. Colloquium Humanarum, Presidente Prudente, v. 15, n. 2, p.22-35 abr/jun 2018.

ROTTA, N. T. Transtorno da atenção: aspectos clínicos. In: ROTTA, N. T. et al. Transtorno da Aprendizagem: abordagem neurobiológica e multidisciplinar. Porto Alegre: Artmed. 2016, p. 274-286. 